NBER WORKING PAPER SERIES

\title{
HEALTH CAPITAL AND THE PRENATAL ENVIRONMENT: THE EFFECT OF MATERNAL FASTING DURING PREGNANCY
}

\author{
Douglas Almond \\ Bhashkar Mazumder \\ Working Paper 14428 \\ http://www.nber.org/papers/w14428
NATIONAL BUREAU OF ECONOMIC RESEARCH
1050 Massachusetts Avenue
Cambridge, MA 02138
October 2008

We gratefully acknowledge comments from seminar participants at the NBER Cohorts meeting Spring 2007, UC Davis, Chicago Harris, the National Poverty Center Life Events Conference, Brown University, Stockholm University (IIES), the NBER Childrens Program, the University of Illinois (Chicago), the Federal Reserve Bank of San Francisco, Notre Dame, the Tinbergen Institute, Bristol University, UVA, Cornell, and the University of Chicago (Booth School of Business). We also thank Lena Almond, Hoyt Bleakley, Janet Currie, Carlos Dobkin, Phoebe Ellsworth, Andrew Gelman, Jon Guryan, Jim Heckman, Hilary Hoynes, Darren Lubotsky, Doug Miller, Kevin Milligan, Diane Whitmore-Schanzenbach, and Kosali Simon for helpful comments. We thank Ana Rocca, Kenley Barrett, Sarena Goodman, and Shyue-Ming Loh for excellent research assistance and Christine Pal for careful copy editing. The views expressed here do not reflect the views of the Federal Reserve system, nor those of the National Bureau of Economic Research.

NBER working papers are circulated for discussion and comment purposes. They have not been peerreviewed or been subject to the review by the NBER Board of Directors that accompanies official NBER publications.

(C) 2008 by Douglas Almond and Bhashkar Mazumder. All rights reserved. Short sections of text, not to exceed two paragraphs, may be quoted without explicit permission provided that full credit, including (C) notice, is given to the source. 
Health Capital and the Prenatal Environment: The Effect of Maternal Fasting During Pregnancy Douglas Almond and Bhashkar Mazumder

NBER Working Paper No. 14428

October 2008, Revised May 2010

JEL No. I1,I12,J1,J14

\begin{abstract}
$\underline{\text { ABSTRACT }}$
We use the Islamic holy month of Ramadan as a natural experiment in fasting and fetal health. In Michigan births 1989-2006, we find prenatal exposure to Ramadan among Arab mothers results in lower birthweight and reduced gestation length. Exposure to Ramadan in the first month of gestation is also associated with a sizable reduction in the number of male births. In Census data for Uganda, Iraq, and the US we find strong associations between in utero exposure to Ramadan and the likelihood of being disabled as an adult. Effects are particularly large for mental (or learning) disabilities. We also find significant effects on proxies for wealth, earnings, the sex composition of the adult population, and more suggestive evidence of effects on schooling. We find no evidence that negative selection in conceptions during Ramadan accounts for our findings, suggesting that avoiding Ramadan exposure during pregnancy is costly or the long-term effects of fasting unknown.
\end{abstract}

\author{
Douglas Almond \\ Department of Economics \\ Columbia University \\ International Affairs Building, MC 3308 \\ 420 West 118th Street \\ New York, NY 10027 \\ and NBER \\ da2152@columbia.edu \\ Bhashkar Mazumder \\ Federal Reserve Bank of Chicago \\ 230 S. LaSalle Street \\ Chicago, IL 60604 \\ bmazumder@frbchi.org
}




\section{Introduction}

Restricted maternal nutrition during critical windows of fetal development can lead to adaptive physiologic responses that are irreversible and later lead to poor adult outcomes [Gluckman and Hanson, 2005]. Recent studies by economists have utilized exogenous shocks "caused by conditions outside the control of the mother" [Currie, 2009] to provide compelling observational evidence on the importance of prenatal development, which can impact both subsequent health capital and skill formation [Cunha and Heckman, 2007]. These studies have typically leveraged uncommon and severe historical events, such as exposure to famine or infectious disease, for identification. It has yet to be established, however, whether more commonly encountered circumstances also exert significant longterm effects. Such exposures are not only more directly relevant to the physiologic pathways described in the biomedical literature, but also may be more amenable to policy intervention.

In this study, we consider a common early-childhood exposure that is ongoing today: disruptions to the timing of prenatal nutrition from meal skipping or dieting during pregnancy. ${ }^{1}$ Specifically we consider the effects of maternal fasting. Muslims generally fast each day during the lunar month of Ramadan. Fasting includes abstaining from eating and drinking during daylight hours. Certain persons are automatically exempted from fasting: "children, those who are ill or too elderly, those who are traveling, and women who are menstruating, have just given birth, or are breast feeding" [Esposito, 2003]. Pregnant women are not explicitly exempted. Three in four Muslim pregnancies overlap with Ramadan and surveys indicate the majority of pregnant Muslims observe the fast.

Previous studies have shown that fasts associated with Ramadan during pregnancy can lead to sharp declines in maternal glucose levels along with other biochemical changes [Prentice et al., 1983, Malhotra et al., 1989]. The supply of glucose and oxygen are considered to be the key signals of the maternal environment during early embryonic development and disruptions in their availability can lead to permanent physiological adaptations that may later lead to disease [Gluckman and Hanson, 2005]. Therefore, repeated maternal fasting during pregnancy may present a more direct way to assess

\footnotetext{
${ }^{1}$ Nearly 1 in 4 women report skipping meals during pregnancy in the US [Siega-Riz et al., 2001].
} 
the long term effects of alterations in the fetal environment than other more indirect treatments such as exposure to disease. We provide new evidence on fasting's effects on birth outcomes and the first evidence of effects later in life using large-sample microdata on Muslims in the United States, Iraq, and Uganda.

Our methodological approach addresses a key flaw in previous studies of Ramadan fasting and birth outcomes. These epidemiological studies have compared pregnant women who fasted to those who did not at a point in time, under the basic assumption that the decision to fast is exogenous. ${ }^{2}$ Instead, we compare births over many years where Ramadan overlaps with pregnancy to those where Ramadan does not and estimate the reduced form effect of Ramadan's timing. ${ }^{3}$ That is, we estimate an "intent to treat" (ITT) effect without relying on the decision whether to fast for identification. ${ }^{4}$ This approach yields distinct ITT estimates for specific months of gestation; Muslim births where Ramadans falls in the early postnatal period serve as the control group. Because Ramadan follows a lunar calendar, its occurrence moves forward by roughly 11 days each year. Thus, we can disentangle the effect of prenatal overlap with Ramadan from season of birth, which is also related to health in adulthood [Doblhammer and Vaupel, 2001, Costa and Lahey, 2005, Costa et al., 2007, Buckles and Hungerman, 2008].

Using natality data from Michigan, we find that prenatal exposure to Ramadan lowers birth weight and reduces gestation length. Further, the likelihood of a male birth is about $10 \%$ lower when Ramadan falls very early in pregnancy and occurs during the peak period of daylight fasting hours. Using Census data for the United States, Iraq, and Uganda we find long-term effects on adult health and economic outcomes. We generally find the largest effects on adults when Ramadan falls early in pregnancy. Rates of adult disability are roughly $20 \%$ higher, with specific mental disabilities showing substantially larger effects. Our estimates are conservative to the extent that Ramadan is not universally observed. Importantly, we detect no corresponding outcome differences when the

\footnotetext{
${ }^{2}$ Pre-pregnancy BMI, along with other characteristics, has been found to predict fasting observance [Kavehmanesh and Abolghasemi, 2004].

${ }^{3}$ We do not observe whether mothers fasted in our data. See Section 6.

${ }^{4}$ We draw an analogy with research designs where there is random assignment to treatment and control groups but where compliance may be endogenous. In our case we assume that the timing of Ramadan relative to pregnancy is exogenous, but that the decision to fast is endogenous and is not universally observed.
} 
same design is applied to non-Muslims as a falsification test.

As we discuss in Section 2, our findings are plausible in the context of the biomedical literature where studies have documented that even relatively short fasts result in dramatic changes in the metabolic biochemical profiles of pregnant mothers, a phenomenon known as "accelerated starvation". For this reason, medical authorities generally discourage meal skipping during pregnancy. Accelerated starvation has specifically been found in the context of Ramadan fasting in multiple countries suggesting that Ramadan is of direct relevance to more general concerns about meal skipping or dieting during pregnancy. The altered metabolic profiles that occur with fasting have been associated with diminished cognitive function during childhood and experimental animal studies suggest that these alterations may hamper neurological development. One recent study has documented heightened levels of the hormone cortisol among pregnant women fasting during Ramadan [Dikensoy et al., 2009], which has been associated with adverse long-term health effects through fetal programming of the neuro-endocrine system. Our results are also consistent with studies of the Dutch famine and 1918 Influenza Pandemic which found particularly large long-term health effects associated with early-pregnancy exposure. Several studies have also documented that maternal nutrition during pregnancy varies positively with male births (in the cross-section). One specific hypothesis suggests that a drop in maternal glucose levels provides a signal of a poor future environment leading to fewer completed pregnancies of male offspring.

Our identifying assumption is that pregnancies are not timed relative to Ramadan along unobserved determinants of health. We present evidence that pre-determined maternal and paternal characteristics are not systematically related to the timing of conception relative to Ramadan. In our Michigan data, we observe maternal education, whether previous birth was low birth weight, maternal diabetes, whether mother smoked, and whether Medicaid paid for the delivery: each is unrelated to the timing of pregnancy relative to Ramadan. Not surprisingly, controlling for these factors has a negligible effect on our ITT estimates.

The remainder of the paper is organized as follows. Section 2 describes previous epidemiological work on Ramadan and health, referencing additional supporting material in the Appendix. Section 3 describes our natality and Census data, ITT measures, and 
econometric model. Section 4 presents our results for birth outcomes in Michigan and Section 5 describes our findings for adult outcomes in Uganda, Iraq, and the US. Section 6 synthesizes and interprets our results and discusses future research.

\section{Previous Literature}

We briefly discuss previous studies relating maternal fasting to health or human capital outcomes. In the interest of space, we refer the reader to additional background material in Appendix, Section A. ${ }^{5}$ In discussing previous work on fasting and health it is instructive to separate studies that have evaluated: 1) measures of maternal and fetal health during pregnancy, and; 2) health at birth. In contrast to prenatal health, measurement of newborn health is relatively standardized (e.g., by birth weight or infant mortality). However, studies of maternal and fetal health allow for comparisons over time for the same pregnancy - in and out of the fasting state - addressing the potential endogeneity of the fasting decision.

Our review of the previous literature is distilled into several hypotheses that are laid out in Appendix Table A1 which we use to inform our analysis. The table highlights which outcomes may be affected and which specific months of pregnancy are most vulnerable to exposure to fasting for each outcome. Fasting early in pregnancy is most likely to matter for adult outcomes whereas birth outcomes (e.g. birthweight) could potentially be affected throughout gestation.

\subsection{Ramadan and Health During Pregnancy}

Writing in The Lancet, Metzger et al. [1982] documented a set of divergent biochemical measures among pregnant women who skipped breakfast in the second half of pregnancy. Relative to twenty-seven non-pregnant women with similar characteristics, "circulating fuels and glucoregulatory hormones" changed profoundly in twenty-one pregnant women when the "overnight fast" was extended to noon on the following day (relative to post-

\footnotetext{
${ }^{5}$ Appendix Section A summarizes the effects of fasting on caloric intake and weight gain; the rates of observance of Ramadan fasting by pregnant women; the potential health effects of maternal biochemical changes on offspring; fasting and fetal programming; studies of Ramadan fasting's effect on birth outcomes; and our hypotheses relating specific periods of exposure to particular outcomes.
} 
prandial baseline). Further, plasma glucose and alanine was lower in the pregnant women than in the non-pregnant women after 12 hours of fasting while levels of free fatty acids and beta-hydroxybutyrate, a ketone, were significantly higher. This set of biochemical changes, also known as "accelerated starvation", occurred after only "minor dietary deprivation" for both lean and obese women. Metzger et al. [1982] concluded that mealskipping "should be avoided during normal pregnancy." Meis and Swain [1984] found that daytime fasts during pregnancy caused significantly lower glucose concentrations than nighttime fasts. Accelerated starvation has been associated with diminished cognitive function [Rizzo et al., 1991] and animal studies have linked ketone exposure very early in pregnancy to neurological impairments[Hunter and Sadler, 1987, Moore et al., 1989, Sheehan et al., 1985]. Gluckman and Hanson [2005] emphasize the importance of glucose supply during early embryonic development noting that "the developing embryo will change the relative assignment of cells to the inner cell and outer cell mass according to whether it perceives a problem in glucose supply" and show that among rats "poor maternal nutrition at this stage produces offspring with higher blood pressure".

According to survey data, most pregnant Muslims observe the Ramadan fast (See Appendix Section A.1.2 for details). Following the study of breakfast skipping by Metzger et al. [1982], Ramadan fasting was likewise found to cause accelerated starvation among pregnant women in Gambia [Prentice et al., 1983] and in England [Malhotra et al., 1989]. Mirghani et al. [2004] found that maternal glucose levels were lower in the fasting state compared to the postprandial baseline, a difference accentuated by the number days fasted: "the effect on maternal glucose levels during Ramadan fasting is cumulative." Several studies of maternal fasting during Ramadan have found adverse effects carried over to measures of fetal health: fetal breathing movements and fetal heart rate accelerations [Mirghani et al., 2004, 2005].

Recently, Dikensoy et al. [2009] reported that Ramadan fasting is associated with increases in cortisol levels during pregnancy, but not for non-fasting pregnant women (both relative to pre-pregnancy levels). This finding is of interest because cortisol is a stress hormone frequently invoked as a potential mechanism through which prenatal experiences may "program" adult health [Kapoor et al., 2006] (See Appendix Section A.3 for more details). 
To summarize, there is fairly consistent evidence that fasting during pregnancy has a "first-stage" effect on maternal and fetal health measures. We summarize the literature on potential fasting sequelae in Appendix Section A. Despite uncertainty whether these first stage effects carry over to birth outcomes and longer-term effects (See Section 2.2 below), the Institute of Medicine nevertheless recommends pregnant women should "eat small to moderate sized meals at regular intervals, and eat nutritious snacks" [Institute of Medicine, 1992:45]. Similarly, the American College of Obstetricians and Gynecologists recommends that pregnant women avoid skipping meals. ${ }^{6}$

\subsection{Ramadan and Perinatal Health}

Whether there is an effect of fasting on birth outcomes has not been established. However, it is important to note that measures of birth size are highly imperfect proxies for capturing nutritional disruptions during embryonic or fetal development [Gluckman and Hanson, 2005]. Therefore, the absence of a finding of effects of fasting on birth weight, for example, does not preclude the possibility of adverse effects on long-term outcomes. Nevertheless it is useful to review the previous literature on fasting and birth outcomes. Most previous studies have drawn comparisons over only a single Ramadan season. Since the panel-data dimension is generally absent for analyses of birth outcomes, studies have resorted to strong assumptions on the comparability of fasters and non-fasters. These two groups are likely different in ways that would generate differences in birth outcomes absent any causal effect of fasting. Pre-pregnancy BMI, along with other characteristics, has been found to predict fasting observance [Kavehmanesh and Abolghasemi, 2004]. This basic weakness in design has been exacerbated by: 1) small sample sizes that in general would only be able to distinguish quite large effects from zero; 2) consideration of Ramadan fasts observed exclusively in mid or late gestation. We refer the reader to the more detailed discussion of these studies in Appendix A.4.1.

No previous study has exploited idiosyncratic variation across birth cohorts in the timing of Ramadan relative to birth. As Ramadan's forward movement through the western calendar is slow, the separation of Ramadan from seasonal effects on birth outcomes (e.g.,

\footnotetext{
${ }^{6}$ http://www.acog.org/publications/patient_education/bp087.cfm?printerFriendly=yes
} 
Doblhammer and Vaupel [2001], Costa and Lahey [2005]) requires data across many birth years. Data availability, therefore, may have precluded implementation of an ITT analysis like ours. Similarly, no previous study has exploited the number of daylight hours during the Ramadan fast for identification (which is clearly not feasible for populations living near the equator, e.g., in Uganda or Indonesia).

Finally, ours is the first study to analyze the relationship between outcomes in adulthood and in utero Ramadan exposure. The study closest to ours in this respect is by Azizi et al. [2004] who found no significant difference in the IQ's of school-age children by maternal fasting behavior during the third trimester (please see Appendix Section A.4.2 for details). Subsequent to our study, Ewijk [2009] analyzed IFLS data from Indonesia, finding evidence of long-term effects of fasting. ${ }^{7}$

\section{Data and Methodology}

Our identification strategy requires microdata with information on:

1. a substantial number of Muslims;

2. precise information on birth date (i.e., more detailed than age in years);

3. coverage of many birth cohorts (i.e., birth years);

4. health outcomes.

In datasets with a large number of both Muslims and non-Muslims, we would also like to distinguish between these groups. We summarize the handful of suitable datasets below (see Appendix B for details), followed by our econometric approach.

\subsection{Michigan Natality Files}

From Michigan's Division for Vital Records and Health Statistics, we obtained birth certificate microdata for 1989 to 2006 in Michigan - approximately 2.5 million birth records. ${ }^{8}$

\footnotetext{
${ }^{7}$ Ewijk [2009] graciously notes that we are "the first to systematically examine [Ramadan's] long-term effects."

${ }^{8}$ We thank Michael Beebe and Glenn Copeland in Michigan's Vital Statistics Office for their assistance with these data.
} 
Although, there is no information on religion, ancestry of the mother is reported (ancestry information is not recorded in the national vital statistics data produced by NCHS). This feature of Michigan's natality data allows us to construct a proxy for whether the mother is Muslim based on reported "Arab" ancestry (or reported ancestries from predominantly Muslim countries). ${ }^{9}$ Compared to other US states, Michigan has a relatively large Arab population. ${ }^{10}$ There are a total of about 50,000 births to mothers of Arab ancestry (about 2.2 percent of MI births) over this period. While there is a large population of Arabs around Detroit, the Arabs are reasonably dispersed throughout the State (see Appendix Figure A2, Panel A).

Since a large fraction of Arabs in Michigan are actually Chaldeans - a sect of Christianity - our proxy may misclassify many mothers and thereby attenuate our estimated effects. ${ }^{11}$ We use the 2000 US Census SF3 (1 in 6 sample) data to identify Michigan zipcodes with heavy concentrations of Chaldeans - who presumably do not observe the fast - relative to Arabs (see Appendix Figure A2, Panel B). In some specifications, we will drop observations from these zipcodes to compare ITT estimates. Appendix Table A2 provides summary statistics for Michigan's natality data.

\subsection{Data from National Censuses}

To consider whether health in adulthood is affected by prenatal Ramadan exposure, we analyze Census microdata for the three countries where our identification strategy can be implemented in publicly-available data. Data from the Uganda 2002 Census are best suited for our analysis because religion is reported, there are large numbers of both Muslims and non-Muslims in Uganda, month of birth is reported, and a host of disability measures are queried. While less well-suited to our analysis, 1997 Iraq Census data and US Census data allow us to assess whether the basic Uganda results are replicated in other settings.

\footnotetext{
${ }^{9}$ See Section B.1 of the Appendix for more detail.

${ }^{10}$ We thank Carlos Dobkin (UCSC) for suggesting we focus on Michigan's Muslim population.

${ }^{11}$ According to the 2000 Census, about a quarter of those of an Arabic speaking ancestry in Michigan are Chaldean Christians. Our estimates based on the Detroit Arab American Study (DAAS) suggest that about $47 \%$ of those who self-identify as "Arab American" in the Detroit area are Chaldean.
} 


\subsubsection{Uganda Census 2002}

Our sample of Muslim adults includes approximately 80,000 men and women between the ages of 20 and 80 in 2002. Muslims constitute about 11\% of Uganda's population and have more schooling and lower rates of disability than non-Muslims (Appendix Table A3). Both Muslims and non-Muslims share a strong seasonality in the number of births. Muslims tend to live in the southeastern portion of the country.

Unlike other national censuses, the Uganda Census asks a battery of questions about specific disabilities, including: blindness or vision impairments, deafness or hearing impairments, being mute, disabilities affecting lower extremities, disabilities affecting upper extremities, mental/learning disabilities, and psychological disabilities (lasting six months or longer). As only about $5 \%$ of adults report a disability compared to over $10 \%$ in the US Census, disabilities recorded in the Uganda Census may be more severe. Further, Uganda reports information on the origin of disabilities: congenital, disease, accident, aging, war injury, other or multiple causes. In the absence of direct measures of economic status we use home ownership. We also consider several other socioeconomic outcomes such as literacy, schooling, and employment.

\subsubsection{Iraq Census 1997}

Although religion is not reported in the Iraq Census, roughly $97 \%$ of the population is Muslim, minimizing concerns about misclassification of religion. Our main sample includes over 250,000 individuals born from 1958 to 1977 who were between the ages of 20 and 39 in 1997 and for whom we have reliable information on birth month. ${ }^{12}$ Because we only cover 20 birth cohorts compared to 60 in Uganda, we may be more concerned about confounding from seasonality. In addition, although our sample size is large this is offset to some degree by surprisingly low rates of reported disabilities. At 1.5\%, Iraqis are substantially less likely than Americans (around 12\%) or Ugandans (around 5\%) to report a disability. Part of this is of course, due to the fact that we have a younger sample. Along with a general disability question, there are specific questions about disabilities involving sight, hearing, lower extremities, upper extremities, and psychological disabilities. In

\footnotetext{
${ }^{12}$ Only 20 percent of those born prior to 1958 provide reliable data on birth month. We discuss these data limitations in greater detail in Appendix section B.3
} 
contrast to Uganda, there is no variable to assess mental/learning disabilities.

In addition to home ownership, we consider a second proxy for wealth/status, polygyny. Under Iraqi law, courts may only allow polygyny if husbands are able to financially support multiple wives and if they are able to maintain separate households for each wife. $^{13}$ (Iraq Legal Development Project, 2005). More generally, polygyny reflects high male status [Edlund, 1999]. Since polygyny is relatively infrequent for a young sample, we expand our sample to include up to 45 year olds. Sample means for our outcomes are shown with the regression results in Table 7.

\subsubsection{US Census 1980, ACS 2005-2007}

Our third Census sample is composed of immigrants to the US who were born in predominantly Muslim countries. ${ }^{14}$ We use a 6\% sample from the 1980 Census along with a pooled sample of the American Community Surveys (ACS) for the years 2005 through 2007 (3\% sample). The ACS is modelled on the long form of the decennial Census. We use these years because they provide the quarter of birth. ${ }^{15}$ Not observing birth month dulls the empirical comparisons that we can make. On the positive side, we obtain a large, national sample of US immigrants from Muslim countries in which to implement our ITT analysis. Data quality is high, and includes additional outcomes beyond disability, such as earnings. ${ }^{16}$ Selected sample means are shown at the bottom of Table 8.

\footnotetext{
${ }^{13}$ Under Iraqi Personal Status Code Number 188, Article 3(4) it is written that: Marriage of more than one wife is prohibited in the absence of judicial permission on two conditions: (a) The husband has financial sufficiency to marry more than one wife. (b) He should have a legal interest.

Iraqi Personal Status Code Number 188, Article 26 states that: The husband should not house his second wife in the same house with the first one without her approval, and should not house any other relative with her without her approval, except his minor child.

Roughly $2 \%$ of Iraqi men report polygynous unions.

${ }^{14}$ Specifically, we use countries with at least an 80 percent Muslim population. To asses the magnitude of misclassification attributable to this birth-county proxy, the same proxy variable was created in the 2001 Canada Census, which includes self-reported religion. 67\% of Canadian immigrants from these $80 \%$ Muslim countries reported being Muslim. We thank Kevin Milligan (UBC) for this information. See Appendix Section B.5 for additional details.

${ }^{15}$ In addition to not knowing birth month, we do not know the exact birth year in the ACS since it is not asked and age is not reported as of a specific enumeration date as it is in the decennial Census. Given that Ramadan exposure shifts by only 11 days from year to year, using survey year - age provides a good approximation of birth year for the purposes of constructing Ramadan exposure measures at the quarterly level. The correlation between Ramadan exposure using survey year minus age, and survey year minus age minus 1 , is about 0.93 .

${ }^{16}$ Specifically we take the log of annual earnings and use the CPI for inflation adjustment. For consistency, we restrict the sample to ages between 20 and 80. Earnings are restricted to a sample between the
} 


\subsection{Ramadan Measures}

We record start and end dates for the 104 Ramadans in the 20th century and construct the following measures of prenatal Ramadan exposure: ${ }^{17}$

exppct calculates the fraction of days over the subsequent 30 days that overlap with Ramadan.

exphrspct utilizes the number of daylight hours in each day to proxy for the length of the Ramadan fast. ${ }^{18}$ The numerator is the number of daylight hours over the next 30 days that overlap with Ramadan; the denominator is the maximum number of daylight hours over any 30 day period over the entire sample period (which depends only on latitude). Daylight hours in Michigan vary from a low of around 9 to a high of over 15 at the summer solstice when the effects of accelerated starvation may be most evident. Please see Appendix Figure A3 for a an illustrative example of exphrspct versus exppct coding from 1989 (and the associated description in Appendix Section B.1).

rampct is the fraction of days in each month that overlap with Ramadan. ${ }^{19}$ rampct is used when we observe just the birth month, as in our Uganda and Iraq samples and is calculated for each month (not each day as for measures above). As Uganda is at the equator, the number of daylight hours is fairly constant over the year at 12 .

Each of the above measures is calculated at up to nine different points in time corresponding to the gestation months (ten in some specifications where we include the month prior to conception). exppct and exphrspct are calculated for the day beginning each pregnancy month. This feature of our research design is useful as specific health outcomes ages of 20 and 60 .

${ }^{17}$ Many websites translate dates from the Islamic (Hijri) calendar. We used the following website http://www.oriold.unizh.ch/static/hegira.html, but verified the dates from a second source.

${ }^{18}$ The beginning of the Ramadan fast actually precedes sunrise and begins at the time of the morning prayer (fajr). The precise timing of the morning prayer may vary across mosques and typically depends on a rule regarding the angle of the sun relative to the horizon. For this reason we actually understate the number of fasting hours in our data. Daylight hours are measured for the city of Dearborn which contains a large share of the state's Arab population.

${ }^{19}$ We opted to use this measure, rather than a simple dummy variable since it provides a continuous measure of treatment (more power). 
may be more or less susceptible to nutrition depending on the stage of pregnancy (see Appendix Table A1 and accompanying text in Appendix Section A). Finally, we construct a fourth exposure measure by taking the average of rampct for each quarter of the year. This quarterly measure is used for our US sample, where we observe just the quarter of birth.

In general, we assign the Ramadan ITT by counting backwards from the birth date. We consider alternatives to this approach where we have estimates of gestation length (Michigan). In the rest of our data, we do not observe gestation length. Furthermore, measurement error in gestation length, commonly based on date of last menstrual period, may be substantial [Pearl et al., 2007]. For Michigan, we consider the following three assignment rules:

1. The first approach uses the exact date of birth and simply assumes that all births have a normal gestation length of 40 weeks since last menstrual period. The Ramadan exposure measures are assigned by going backwards from the birth date in 30 day increments and using daily exposure measures (exphrspct and exppct) from 30 days prior to birth to 270 days prior to birth. Using this approach the measure of Ramadan exposure 9 months prior to birth is a proxy for the actual exposure during the "first month" of gestation.

2. Our second approach incorporates the measures of gestation from the natality data to match each individual to an estimated date of conception. ${ }^{20}$ We then assign Ramadan exposure for the first month based on the daily exposure measures for the date that is 4 days prior to the estimated date of conception. ${ }^{21}$ We then proceed to assign Ramadan exposure measures forward in 30-day increments. Using this approach a child born premature after say, 34-35 weeks of gestation would only have been in utero for about 8 months and therefore only the first 8 exposure variables are actually relevant for birth outcomes.

\footnotetext{
${ }^{20}$ Gestation based on last menstrual period (LMP) is used except if it is missing or if it differs with the physician estimated gestation by more than 14 days, in which case the physician estimated measure is substituted. The conception date is estimated as occurring 14 days after LMP.

${ }^{21}$ This ensures that we have lined up the gestation month exposure in a parallel way to that used in the first approach. In other words, if a birth has exactly 40 weeks or 280 days of gestation, using either approach we will start measuring gestation exactly 270 days prior to birth.
} 
3. Our third approach ignores information on exact birth date and actual gestation and mimics what we can do with our Census samples where we only know month of birth. Here we match individuals to the rampct measure for each of the 9 months prior to birth.

\subsection{Econometric Model}

We regress each outcome, $y_{i}$, on a set of nine Ramadan exposure measures (either exphrspct, exppct or rampct). Separate exposure measures for each gestation month $k$ are included simultaneously in each regression, even though an individual will only be exposed to Ramadan in at most two (adjacent) months of gestation. The effects of Ramadan exposure in a given month of gestation, therefore, are measured relative to no prenatal exposure to Ramadan - i.e., when Ramadan falls in the two to three months after birth.

$$
y_{i}=\alpha+\sum_{k=1}^{9} \theta_{k} \cdot \text { exphrspt }_{k}+\text { year }_{y}+\text { month }_{m}+\text { geog }_{g}+\varepsilon_{i}
$$

Additional controls include birth year dummies, a set of calendar birth month dummies (or conception month dummies if gestation information is used), and a set of dummies that measure geographic location at the time of birth. ${ }^{22}$ In the Michigan analysis we also include a number of largely predetermined variables as additional controls: mother's age, mother's age squared, mother's years of education, father's age, father's age squared, father's education, a dummy for missing father's education, parity, tobacco use during pregnancy, alcohol use during pregnancy, the number of previous pregnancies where the child was born dead, and whether the birth was paid for by Medicaid (an income proxy). ${ }^{23}$ In our pooled samples of adult men and women in Uganda, Iraq, and the US we also include a female dummy.

In a typical specification where we include the nine exposure measures simultaneously, we also run an $F$-test on the joint significance of all nine coefficients. This tests the overall effect of Ramadan exposure during any point in gestation. In addition, since

\footnotetext{
${ }^{22}$ In Michigan we use 84 county dummies. In Uganda we use 56 district of birth dummies. In Iraq we use 18 governates of birth and in the US we use 38 countries of birth.

${ }^{23}$ Parity is defined as the number of previous live births. Alcohol and tobacco use are arguably endogenous since their use may be reduced during the month of gestation that overlaps with Ramadan.
} 
our hypotheses for some outcomes (Table A1) suggest an effect only in specific gestation months, we also run tests of equality of all coefficients.

When we use a non-Muslim sample as a falsification check (in a separate regression), the birth timing and birth location effects are allowed to vary across groups (along with the other parameters). For estimates on population counts by month we use aggregate measures at the cell level where cells are defined by each of the distinct conception or birth months over the sample period. For Michigan, this yields 216 cells $(18$ years $\times 12$ calendar months).

For the adult US sample where we only observe quarter of birth, there is an added difficulty in identifying a control period with no in utero Ramadan exposure. If we assume that all births were of normal gestation length, then individuals were in utero for each of the two quarters prior to the birth quarter, along with some portion of their birth quarter. This would suggest that we use the quarter three quarters prior to the birth quarter as the omitted category. A more conservative approach would treat only those with Ramadan exposure in the two quarters prior to birth as treated and omit both of the other two birth quarters. We will show results using each of the two approaches.

\section{Michigan Results}

\subsection{Birthweight Weight and Gestation}

Table 1 presents the results for birthweight. In the first four columns we assign births their Ramadan exposures by counting backwards from the date of birth (i.e., ignoring the reported information on gestation and assuming pregnancies all had normal gestation length). We designate the coefficients on Ramadan exposure according to the number of months prior to birth.

Columns (1) and (2) use measures of Ramadan exposure that incorporate hours of daylight (exphrspct). The first entry of column (1) indicates that birthweight was about 40 grams lower if an Arab mother was in the first month of pregnancy (i.e. nine months before birth) during the peak period of daylight hours and Ramadan coincided with the first month of gestation. This result is significant at the 5 percent level. In addition, 
gestation months 2, 4, and 6 also show significant negative effects of around 40 grams. We also find that the $F$-test on the joint importance of all the prenatal Ramadan exposure measures is significant at the 8 percent level. The test of the equality of coefficients is not rejected at conventional significance levels.

In column (2), we also include Ramadan exposure 10 months prior to birth as a falsification and robustness check. As expected there is no detectable effect on birth weight and its inclusion does not substantially affect the point estimates for other months. In column (3) we measure Ramadan exposure by the fraction of days in the gestation month that overlap with Ramadan. This treats a Ramadan falling in winter the same as one during summer. It also changes the interpretation of the coefficient to reflect the average effect of Ramadan exposure across all seasons. As expected, this reduces the magnitude of the estimated effects to around 25-30 grams, which remain statistically different from zero. In column (4) we again include exposure in the month prior to the beginning of pregnancy and find no effect. Column (5) ignores information about the exact date of birth and only utilizes the birth month to assign exposure measures of the fraction of days in each month that overlap with Ramadan. With this approach we now find only the second month of gestation to be significant and that the coefficients are far from jointly significant or significantly different from one another. Nevertheless, the effect size remains in the 30 gram range. Using only birth month re-allocates some Ramadan ITT assignments to adjacent months. ${ }^{24}$

In columns (6)-(9) of Table 1, we assign Ramadan exposure using the time elapsed since conception, and exclude the $7 \%$ of births that are pre-term ( $<37$ weeks gestation). This ensures that at least the first 8 exposure measures are reasonably interpretable since all of these births would have been in utero for 8 months. ${ }^{25}$ Columns (6) and (7) utilize the daylight hours index of exposure. We find effects that are statistically significant at the 5 percent level for exposure in month 1 . As in columns (1) and (2), the size of these effects are between 35 and 40 grams. In column (7) we again show no effect in the month prior to conception. Thus, the pattern of birth weight effects we find are not an artifact

\footnotetext{
${ }^{24}$ For example, the effect of Ramadan falling nine months prior to birth in column (4) appears smoothed into the adjacent month (8 months before birth) in column (5).

${ }^{25}$ In our tables we use italics to signify estimates that may include post natal exposure for some sample members.
} 
of assigning the Ramadan ITT using date of birth. Columns (8) and (9) show smaller effects from first month exposure when seasonal differences in the length of the diurnal fast is ignored. The smaller sample used in columns (6) through (9) that ignores gestation length have considerably higher significance levels on our joint test of an effect across all gestation months (i.e., when we drop premature births and estimate the specifications in columns (1)-(5)). This suggests that part of the difference between the two panels of Table 1 may be due to selection on nearly full-term births. For example, the magnitude of the effects for Ramadans that fall 4 months prior to birth are attenuated in the full term sample.

We explore the role of conditioning on different gestation lengths and using a more restricted sample of zipcodes that excludes zipcodes with a large fraction of Christian Arabs (Chaldeans) in Appendix Table A4. We note that when we condition on fullterm births (39-42 weeks) and restrict the sample to those with a likely higher degree of adherence to the fast we find larger ITT effects that are also significant in mid-gestation months 5 and 7 . The associated text in the Appendix discusses impacts on gestation length itself, which are modest compared to those for intrauterine growth retardation (IUGR).

\subsection{Refutability Check Using Non-Arab Births}

Identification of our ITT estimates comes from an idiosyncratic, non-linear function of date of birth. If this function somehow introduced a mechanical relationship between birth date and health outcomes (e.g. picking up a time trend), it should also be observed among non-Muslims. As a check on the validity of the results above, we apply the same ITT to our non-Arab sample in Table 2. The first six columns assign exposure assuming normal gestation for the whole sample, while the seventh through ninth columns utilize the gestation data and present the results for the sample of full-term births. Within each of these sets of results, we use either all non-Arab mothers or a "super control" group of non-Arab mothers living in zipcodes without any Arabs (according to the 2000 census data). ${ }^{26}$ We find no birthweight effects among non-Arabs comparable to the results in

\footnotetext{
${ }^{26}$ The results are unaffected if we use the natality data to identify non-Arab zipcodes. However, given that we have more confidence in the reporting of ancestry detail in the Census we opted to use those
} 
Table $1 .{ }^{27}$

\subsection{Summary and Discussion of Birth Weight Results}

Overall, in utero exposure to Ramadan is associated with lower birth weight among Michigan's Arab mothers. A full month of exposure to Ramadan during the peak period of daylight hours could lead to a reduction in birth weight of about 40 grams especially when Ramadan falls in the first month of gestation. Nevertheless, the size of this effect is relatively small: 40 grams is only about 1.2 percent of the mean birth weight for Arabs. These effects are population averages and do not account for the fact that some fraction of these women are not actually fasting and more importantly, perhaps, that we may be including a sizable fraction of Non-Muslim women among the Arabs. Table A4 provides suggestive evidence that the effects may be larger and also occur during mid-gestation when we account for these factors. In terms of the birth weight distribution, it appears that most of the estimated effect for early pregnancy exposure is in the middle of the distribution (see Appendix Figure A4), rather than a disproportionate increase in the likelihood of low birth weights. Gluckman and Hanson [2005] emphasize that adaptive responses to nutritional restrictions may occur throughout the birth weight distribution (p.99). On the other hand, increases in low birth weight may be more closely tied to other measures of newborn health than reductions at higher birth weights [Almond et al., 2005]. In any event, since birth weight may be a poor proxy for the underlying effects of nutritional shocks on fetal development (e.g. Franko et al. [2009]), we interpret our findings on birth outcomes conservatively, using them primarily as confirmation that prenatal fasting is indeed having a "first stage" effect on health measured at birth.

Finally, if Ramadan observance during pregnancy varied by socioeconomic or health status, treatments effects would presumably also show a corresponding gradient, other things equal. Interestingly, we observe no systematic gradient in the size of the birth weight effects by maternal education, Medicaid use, or month prenatal care was initiated (results available from authors). If treatment effects are relatively homogeneous, this

\footnotetext{
figures.

${ }^{27}$ In column (3) of Table 2 we obtain two estimates of about -4 grams that are only significant at the 10 percent level, which may be chance occurrences among the 81 reported point estimates.
} 
suggests that fasting observance is high or fairly uniform across socioeconomic groups by month of gestation.

\subsection{Fetal Death and the Sex Ratio at Birth}

Mathews et al. [2008] found that poor maternal nutrition (possibly due to breakfast skipping), around the time of conception skews the sex ratio in favor of girls, most likely through the selective attrition of male conceptuses. Similarly, Almond et al. [2009] found that severe morning sickness in early pregnancy is associated with female births, but also a $50 \%$ fetal death rate due to severe nausea and vomiting. ${ }^{28}$ More generally, maternal nutrition among mammals close to conception is positively associated with the likelihood of male offspring Cameron [2004].

We consider Ramadan's effect on sex at birth and the number of lives births in Table 3. Using our full sample of Arab mothers (column 1) we find a large effect of -3.7 percentage points $(p$-value $=0.06)$ on the likelihood of a male birth from exposure to Ramadan during the longest diurnal fast in month 1 of pregnancy. In column (2) when we restrict the zipcodes to those with fewer Chaldeans relative to Arabs, this point estimate rises substantially to -6.6 percentage points and is significant at the 1 percent level. Interestingly, we find some suggestive evidence of an effect in the month prior to conception possibly reflecting the persistent effect of fasting just prior to conception. Columns (3) and (4) show no analogous effects for our non-Arab samples.

To shed light on the cause of the sex ratio change, we aggregate counts of total births, male births, and female births based on the month of conception. This results in 216 observations for conceptions between April 1988 and March 2006. The mean fraction of births (weighted) that are male is 51.8 percent for Arabs over this period and the mean sex ratio (male to female births) is 1.086. For non-Arabs, the respective means are 51.3 and 1.054. We regressed the log of the number of births on the exphrspct measures of Ramadan exposure including dummies for month and year of conception and our full set of controls.

Results for the more restricted sample of Arabs are shown in columns (5) through (7).

\footnotetext{
${ }^{28}$ By fetal death, we mean any attrition between conception and live birth. This could include attrition during embryonic development before a fetus is fully formed.
} 
Peak exposure to the Ramadan fast in the month after conception is associated with a 16 percent decline in total births. If male vulnerability [Kraemer, 2000] is the culprit, this drop should be concentrated among male births. When we examine this by sex, we indeed find this is driven by a 26 percent drop in male births $(p$-value $=0.005)$, while female births fall by a statistically insignificant 4 percent. ${ }^{29}$ This decline in births associated with fasting around the time of conception is probably not due to other behavioral changes associated with Ramadan since it is difficult to imagine an alternative mechanism which impacts sex-specific fertility.

Among those conceived shortly after Ramadan, (i.e., exposure in month zero, the month prior to pregnancy) there is a statistically insignificant increase of 6.3 percent in total live births associated with full exposure with some suggestive evidence of a female skew. ${ }^{30}$ The fact that total births rise somewhat after Ramadan is not so surprising since the end of Ramadan (Eid ul-Fitr) is a major event for Muslims and is celebrated with a three day period of festivities. ${ }^{31}$ Further, the end of Ramadan marks the end of a restriction on sex during daytime hours and the end of a period of piety. Nevertheless, the increase in fertility is small, statistically insignificant and perhaps skewed toward female births. We address potential selection issues that might arise from fertility changes in section 4.6 .

\subsection{Other Birth Outcomes}

We briefly summarize results for nine other birth outcomes: low birth weight, infant death, APGAR scores, maternal weight gain, NICU unit, C-section, abnormal conditions, and congenital anomalies. We used three different specifications and two different samples but found that many of the results were sensitive to these choices. ${ }^{32}$ Appendix Table A5 shows results with our more restricted sample of zipcodes and the broadest sample

\footnotetext{
${ }^{29}$ Several other gestation months show larger drops for female births associated with Ramadan exposure.

${ }^{30}$ The increase in male births (one third of one percent) lags female births (9 percent). When we use our full sample of Arab births (not shown) the increase in total births is 4 percent with male births rising by 0.5 percent and female births rising by 6.5 percent.

${ }^{31}$ In Hong Kong natality microdata, the lunar new year celebration is associated with a comparable increase in births approximately nine months later (results available from authors).

${ }^{32}$ We varied gestation length (25-42 weeks, 37-42 weeks, and 39-42 weeks) and whether we used the full sample of Arabs or the more restricted sample of zipcodes.
} 
in terms of gestation (25-42 weeks) where only the first 5 gestation month coefficients are readily interpretable (due to to compositional effects). The most consistent finding concerned lower maternal weight gain due to exposure in the 7th month of gestation that is apparent in all of our samples, though not always statistically significant. While maternal weight gain might appear to be a desirable "first stage" measure, it has at least one (unobserved) self-reported component (pre-pregnancy weight) and thereby suffers from substantially more measurement error than newborn's birth weight [Schieve et al., 1999] .

\subsection{Selective Timing of Conceptions Around Ramadan}

Our identifying assumption is that the composition of Muslim parents does not change systematically by their children's in utero exposure to Ramadan. A general concern could be that mothers of higher socioeconomic status (SES) seek to avoid having pregnancies overlap with Ramadan by concentrating conceptions during the two to three months just after Ramadan. ${ }^{33}$ Another concern could be if less healthy or less educated women are more likely to conceive in the month prior to Ramadan which might account for our consistent findings on first month exposure. Finally, although we did not detect a statistically significant increase in conceptions following Ramadan, one might be concerned that there is selection associated with which parents conceive just after Ramadan due to general behavioral changes in society during this festive period.

We assess whether Ramadan exposure during pregnancy and the month prior to conception is associated with a set of pre-determined characteristics of the pregnancy that may be correlated with birth outcomes. ${ }^{34}$ Table 4 estimates equation (1) with twelve "outcome" variables: mothers' education, whether the pregnancy was paid for by Medicaid (income proxy), mother's age, father's age, father's education, tobacco use during pregnancy, alcohol use during pregnancy, parity, whether a previous child was born dead, an indicator for missing father's education, whether the mother had previously delivered a small baby and whether diabetes was considered a risk factor for the mother. Out of the

\footnotetext{
${ }^{33}$ This might not alter our conclusions concerning differences due to exposure within the gestation period.

${ }^{34}$ Because we only observe those conceptions which result in a live birth, effects of post-conception Ramadan exposure may be manifested in pre-determined characteristics if Ramadan-induced fetal mortality has a gradient in these same characteristics.
} 
120 estimates, only 1 coefficient was significant at the 5 percent level. We found exposure during the last month of pregnancy was associated with lower alcohol use. We found only 4 coefficients that were significant at the 10 percent level and three of them suggested Ramadan exposure was positively selected. For example mothers who had high exposure in the fourth month of gestation had higher education than mothers whose pregnancies did not overlap with Ramadan. Most importantly we found no evidence indicating positive selection in mothers who conceive in the month after Ramadan and no evidence suggesting that mothers who conceive in the month before Ramadan are negatively selected. In an additional check, we have run all of our birthweight and gestation length results dropping mothers who conceived in the month after Ramadan so that our effects are estimated only relative to mother's who conceived two to three months after Ramadan but whose pregnancies did not overlap with Ramadan, and found very similar results. ${ }^{35}$

\section{Census Results}

\subsection{Results from Uganda Census}

Our presentation of potential long-term effects begins with Uganda, where self-reported religion, birth month, and various health outcomes are available for a sizable number of adult Muslims and non-Muslims. As in data from other countries (e.g., the US Census), disability is the primary measure of health in the Uganda Census.

\subsubsection{Disability Outcomes}

Table 5 shows disability outcomes for Muslims and non-Muslims. Because these outcomes have a low incidence rate we have multiplied the coefficients and standard errors by 100 to make them easier to read. The effects are therefore measured in percentage points. In the first column we show the effects of Ramadan exposure over each of the nine months preceding birth. In column (1) we find a statistically significant increase in the likelihood

\footnotetext{
${ }^{35}$ If anything, point estimates tend to increase in absolute value. For example the Table 1 column (6) estimate for the first month of gestation rises to -53.3 from -37.9 with a $p$-value of 0.02 . The Table A4 column (6) estimate of the 2 nd month effect on weeks of gestation is -0.16 rather than -0.11 with a $p$-value of 0.02 .
} 
of a disability (of any kind) for Muslims born nine months after Ramadan (point estimate of 0.819 and $p$-value of 0.02 ). Relative to the mean disability rate of 3.8 percent, the effect is substantial at 22 percent. We find that no other month prior to birth is statistically significant and the $p$-value on the joint test of all nine coefficients does not approach statistical significance. We cannot reject that all of the coefficients are equal.

Turning to specific disabilities (columns (2) to (5)), the most striking finding is the increased incidence of a mental or learning disability (column (4)) when Ramadan occurs during the first month pregnancy. The point estimate is 0.250 with a $p$-value of 0.001 . Given the mean rate of 0.14 percent this implies that the occurrence of Ramadan early in pregnancy nearly doubles the likelihood of a disability related to diminished cognitive function. Thus, the increase in mental/learning disabilities from month-one Ramadan exposure would account for about $15 \%$ of all mental/learning disabilities among Muslims. Furthermore, those with exposure in month 8 have a $100 \%$ increase (significant at the $5 \%$ level) and those with Ramadan exposure in months 5 or 6 show smaller increases (significant at the $10 \%$ level). The joint test on all gestation months of no effect is rejected at the 4 percent significance level.

We also find that the incidence of sight/blindness and hearing/deafness are higher for those born 9 months after Ramadan. Specifically, the magnitude of the effects relative to those not in utero are 33 percent for blindness $(p$-value $=0.07)$ and 64 percent for deafness $(p$-value $=0.04)$. For hearing/deafness we also find a marginally significant effect for those exposed to Ramadan in the fifth month of gestation.

We run the same specifications on our sample of non-Muslims in columns (6) - (10). We find no cases of a corresponding significant result for Muslims also occurring for Non-Muslims for these outcomes. We tested the sensitivity of the results for Muslims to also including exposure during the 10th month prior to birth and found that the results were unaffected and that in no case was the coefficient on the 10th month statistically significant (see Appendix Table A6). We also ran our specifications separately for men and women (not shown) and found that the results were qualitatively similar though the estimates were much less precise. 


\subsubsection{Causes of Disability}

Previous falsification tests have considered Ramadan exposure outside of pregnancy and Ramadan exposure during pregnancy for non-Muslims. Information on the causes of disabilities provides a third falsification test. We group these reported causes - accident, occupational injury, war injury, aging, disease, or congenital - by whether they can reasonably be linked to fasting via the mechanisms discussed earlier. Clearly, disabilities that arise from accidents, occupational injuries, or war injuries are postnatal and should not be related to maternal fasting during Ramadan. On the other hand, the fetal origins hypothesis suggests that extended periods of nutritional restriction may be associated with a reprogramming of the body's systems that result in poor health outcomes later in life (see Appendix for additional discussion). This would be consistent with those who report "aging" as the source of a disability. Since it is conceivable that fasting might contribute to a weakened immune system, respondents who report disabilities due to "disease" could plausibly be related to the timing of Ramadan. Finally, whether maternal nutrition affects congenital disabilities (those present at birth) is not clear-cut. ${ }^{36}$

We find no significant effects from accidents, occupational injury or war injuries for Muslims or non-Muslims in any gestation month (Appendix Table A7). In contrast, Muslims born nine months after Ramadan have an increased incidence of disabilities due to aging of 0.37 percentage points $(p$-value $=0.006)$. We find no evidence linking Ramadan exposure to disease-related or congenital disabilities (consistent with Michigan results for congenital anomalies). We found no comparable effect of first month exposure to Ramadan on disabilities caused by aging for non-Muslims. ${ }^{37}$

In order to address possible concerns about selective timing of pregnancy in Uganda, we used a sample of children aged 17 or under and living with their parents and regressed parent characteristics (education, illiteracy, and disability) on the child's Ramadan exposure using equation (1). As with Michigan, we found no statistically significant effects of negative selection on parent characteristics. Finally, we also found that the results were insensitive to excluding outlier cohorts that had extremely large or small disability rates.

\footnotetext{
${ }^{36}$ If the disability is epigenetic then it may be associated with maternal fasting.

${ }^{37}$ Among non-Muslims the only significant effect is that those exposed to Ramadan one month before birth are 0.12 percentage points $(p$-value $=0.017)$ more likely to have a congenital disability. This is a 20 percent effect relative to the mean.
} 
If anything, excluding outliers slightly increased the point estimates and their precision.

\subsubsection{Sex Composition of Adult Population}

With the Uganda data we explore the possibility that maternal fasting may influence the sex composition of the adult population. This could arise either from alterations to the sex composition at birth or because of selective mortality by sex after birth as implied by some of the fetal origins literature (see Appendix Section 1). To assess this, we conduct an analysis parallel to our Michigan analysis. First we simply regress male as an outcome in equation (1). Second, we aggregate the population by cells constructed by birth month both for the pooled sample as well as separately by sex and take the log of the population counts as an outcome.

Results are shown in the left most panel of Table 6. In column (1) we find that every implied gestational month has a negative coefficient and that the 1st, 4th and 7th months of gestation are statistically significant at the 5 percent level The joint test of all the exposure months is significant at the 10 percent level. In column (2) we find only slight evidence cohort size is related to Ramadan exposure when we pool men and women. When we look at the log of population counts of males in column (3), seven of the nine months have negative coefficients and the 7th month of gestation has a particularly large and statistically significant effect (15\%). The effects on the sex in column (1) appear to be driven by reductions in the number of males. In column (4) we show the analogous results for women where the effects are all positive but only significant in one month. In other results (not shown) we find no comparable effects on the sex composition for non-Muslims.

\subsubsection{Other Outcomes in Uganda}

The remaining columns of Table 6 show results for non-health outcomes. Unfortunately preferred economic outcomes, such as wages, income, and wealth, are not available. In column (5) we examine whether home ownership, a proxy for wealth, is affected. We restrict the sample to men since they are the vast majority of property owners in Uganda. ${ }^{38}$

\footnotetext{
${ }^{38} \mathrm{Uganda}$ is a patriarchal society where land is passed down through sons. Although women are not prevented from owning land, by one estimate, 93 percent of Ugandan land is owned by men.
} 
We find that men exposed to Ramadan in the first month of gestation are 2.6 percentage points less likely to own their home $(p$-value $=0.027)$ and that men exposed in the 2 nd month of gestation are 2.1 percentage points less likely to own their home $(p$-value $=0.051)$. Given the high rate of male home ownership (73.4 percent), these effects are not especially large. We can reject that there is no effect of Ramadan exposure over all gestation months on home ownership at the 5 percent level. In contrast, we find no statistically significant effects of Ramadan exposure on home ownership for non-Muslims.

In columns (6) through (9) we examine illiteracy, completed years of schooling, a dummy for no schooling, and employment status at the time of the Census. We find no statistically significant effects that associate greater Ramadan exposure with higher illiteracy or lower schooling. In fact those born 8 months after Ramadan appear to have higher human capital levels by both of these measures. The magnitude of these effects, however, is very small. For example, the increase in years of schooling for these individuals is only about a tenth of a year, or 1.6 percent of the sample mean.

In developing countries a reduction in health capital could be manifested in less productive childhood labor and possibly lead to increased schooling. We also speculate that these small but positive results might reflect a selective effect on surviving males, who seem to bear the brunt of Ramadan-related attrition (either prenatally or postnatally). In developing countries where average mortality rates are high, the selective effect of health disruptions operating through early-life mortality may overwhelm "fetal origins" effects on adult survivors [Deaton et al., 2009]. Scotland [1956] provides supportive evidence that death rates among the frail were very high in Uganda during roughly the middle of our sample period in the 1950s. When we split the sample by gender, we only found these positive education effects for men and found negative (though insignificant) effects on women. When we split the sample by those above age 50 versus those aged 50 or younger, the effects are much larger for the older groups. These facts are consistent with the possibility of sex-specific selective mortality.

(http://www. womensenews.org/article.cfm/dyn/aid/1456/context/archive). 


\subsection{Results from Iraq Census}

We replicate the basic Uganda results using 1997 Iraq Census data. Columns (1) to (4) of Table 7 show the effects on disability. Full exposure to Ramadan nine months before birth is associated with a 0.33 percentage point increase in the probability of having a disability $(p$-value $=0.016)$. While in Uganda the overall disability rate was 3.8 percent, in Iraq it is just 1.5 percent. However, the effect size relative to the mean in Iraq is 23 percent, nearly identical to the 22 percent effect size that we estimated in Uganda. In Iraq the rates of disabilities involving sight and hearing, however, are a much smaller fraction of the reported rates for Uganda and this may explain why we detect no effect on these measures for first month exposure in columns (2) and (3). ${ }^{39}$ We do find that exposure in month 5 of pregnancy has an effect on vision related disabilities.

"Insane" is the sole mental disability queried, which IPUMS relabeled as "psychological" disability. Interestingly, at 0.36 percent, Iraq's psychological disability rate is actually higher than the combined rate of 0.28 percent for mental/learning plus psychological disabilities in Uganda (despite Iraq's lower overall disability rate). This suggests that mental/learning disabilities that are related to cognitive impairments may be subsumed in the psychological disability measure for Iraq. In column (4) we find strong effects on psychological disabilities just as we did for mental/learning disabilities in Uganda. First month exposure to Ramadan is associated with 0.23 percentage point increase in the likelihood of a psychological disability or a 63 percent effect relative to the mean ( $p$-value $=0.001)$. We also estimate positive but insignificant effects in 6 of the other 8 gestation months. As was the case in Uganda with mental/learning disabilities, the joint test of zero effect across all gestation months is easily rejected at the 5 percent level, as is the test of equality of coefficients. The fact that both overall disability as well as disabilities that likely capture cognitive impairments appear to be impacted in precisely the same period of fetal development in two different societies is remarkable and reinforces that our findings are not due to chance.

In columns (5) through (8) of Table 7 we turn to socioeconomic outcomes. ${ }^{40}$ The

\footnotetext{
${ }^{39}$ For vision/blindness only 0.14 percent report this disability which is only about one-tenth of the share reporting a comparable disability in Uganda. For deaf/hearing only 0.02 percent report this disability which is only one-sixteenth of the rate found in Uganda.

${ }^{40}$ We experimented with measures of human capital such as years of schooling and illiteracy but found
} 
1997 Iraqi Census asks about instances of men having multiple wives which we use to proxy for wealth (as described earlier). For this measure, shown in column (5) we find that men with first month exposure are more than half a percentage point less likely to have multiple wives and negative point estimates are found throughout pregnancy. A large and significant effect is also found during month 6 of gestation. Similarly, for home ownership (column 6), we see highly significant effects of exposure throughout the in utero period and the joint test of all gestation month coefficients is significant at the 8 percent level. In column (7) we see no effects on the sex composition of the adult population which may not be so surprising given that Iraq's sex ratio is already skewed toward women. Finally, in column (8) we find both small positive and small negative effects of Ramadan exposure on employment that are statistically significant. We note that among males, home owners are less likely to be employed (73\%) than non-home owners (82\%) suggesting that employment may be a poor proxy for economic status in Iraq and may actually signal lower status. ${ }^{41}$ As with our Uganda results, we have also run all of these estimates including exposure 10 months prior to birth and in no case did it meaningfully alter the results.

\subsection{Results from US Census}

The US data provide potentially higher quality measures of disability as well as direct measures of labor market outcomes (unavailable for Iraq and Uganda). As mentioned in Section 3.2.3, the data's chief drawback is absence of month of birth information, which dulls assignment of the Ramadan ITT. On the other hand, findings of long-term effects in the US may address concerns that the Uganda and Iraq results do not generalize to Muslims living in a high-income Western society.

Panel A of Table 8 presents results for four outcomes across three samples. In each regression we estimated effects of Ramadan exposure in one's birth quarter and in the

that there were extremely strong month of birth trends in these variables that could not be adequately controlled for without having a full set of birth cohorts for whom Ramadan occurred throughout the entire calendar year. The seasonality in birth month are likely related to institutional issues concerning education (e.g. cutoff ages for starting or ending school tied to specific dates).

${ }^{41}$ If we control for home ownership and multiple wives the instances of positive effects of Ramadan exposure on male employment are eliminated. 
prior two birth quarters, omitting Ramadan exposure three quarters prior to the birth quarter and thereby treating that cohort as the control group. Since we have averaged our monthly exposure measures within each birth quarter, our quarterly exposure measure never exceeds one third (0.33) in any quarter. Therefore, our coefficients which represent the effect of a unit change in exposure should be scaled down by one-third to be interpretable as the effect of fasting for 30 days within the birth quarter. For this table we have also multiplied all the dichotomous outcomes by 100 .

The first four columns pool samples drawn from the 1980 Census and the 2005-2007 ACS. We find a significant effect of exposure in the quarter prior to birth on the incidence of disability (column (1)). The coefficient of 3.50 suggests that Ramadan's occurrence in a particular month within that quarter would raise the likelihood of a disability by about 1.17 percentage points. Since the mean rate of disability in the sample is 6.07 percent, this implies about a 19 percent effect at the mean, again quite similar to the corresponding magnitudes in Uganda and Iran. The $p$-value on the joint test of the three quarters is 0.01. However, the timing of exposure appears to be concentrated more in the second trimester rather than early in gestation. ${ }^{42}$ Of course it may be that effects are large in the first month of gestation (as in Uganda and Iraq) in addition to the second trimester but we are obviously unable to check this.

In column (4), we find that exposure both in the birth quarter and two quarters prior to birth is associated with a reduction in log annual earnings of about 5.5 to 6 percent (re-scaled). Both estimates are significant at the 5 percent level and the effects are jointly significant at the 0.11 level. To measure human capital we began by examining completed years of schooling as an outcome (not shown) and found a statistically significant effect of about 0.15 years from one month's exposure that occurs two quarters prior to birth. Since this was a relatively small sized effect, we then looked for whether this was concentrated at the low end of the education distribution by looking at failure to complete 12 years of schooling as an outcome ("less than HS"). Column (2) shows a coefficient of 2.513 for Ramadans falling two quarters prior to the birth quarter, significant at the 11 percent

\footnotetext{
${ }^{42}$ Depending on when in the quarter an individual is born, the prior quarter could reflect effects anywhere from the 4 th gestation month to the 9 th. If births were uniformly distributed within a quarter then the mean exposure month would be the fifth month of gestation.
} 
level. The point estimate implies that one month of exposure to Ramadan fasting is associated with about a 0.84 percentage point increase in the high school dropout rate which implies a 6.4 percent effect size evaluated at the mean.

We find negative point estimates for the likelihood of being male (column (3)) that are not statistically significant, but nevertheless potentially meaningful quantitatively. Complete exposure in the quarter two quarters prior to the birth quarter is associated with a roughly 1 percentage point decline in the male share of the adult Muslim population.

The General Accounting Office noted the "impact of measurement error appears to be greater for the ACS" than for the long-form of the decennial US Census [GAO, 2002]. In columns (5) through (8) we restrict the sample to those observed in the 1980 Census, ${ }^{43}$ about a third of the full sample, and observe broadly similar effects. With this sample we also observe that the other two quarters of Ramadan appear to have strong effects on adult disability. So it could be that in 1980, at least, there were in fact long-term repercussions among those whose mothers fasted early in pregnancy. In columns (9) through (12) we restrict the sample to the pooled ACS sample from more recent years. We again see disability effects of a similar magnitude and timing. For both subsamples the effects on earnings are insignificant but if anything appear to be stronger earlier in pregnancy (two quarters prior to the birth quarter).

Panel B takes a more conservative approach in designating the control group. Although we know that the vast majority of pregnancies that overlap with Ramadan's occurrence in the two quarters prior to birth will actually be exposed to Ramadan for the entirety of the three months of the quarter, this is much less likely for the quarter of birth itself and the quarter three quarters prior to the birth quarter. Therefore, here both of these quarters are omitted and serve as the reference group. As can be seen in columns (1) through (4) of Panel B, this does not alter our basic results. The effect size on disability is a bit smaller but still highly significant. The effect on having fewer than 12 years of schooling actually rises, becomes significant at the 5 percent level, and the joint test of both exposure coefficients is now significant at the 8 percent level. On the other hand the effect on earnings drops considerably and is no longer statistically significant.

We have also run all of these specifications on a sample of US born whites that are

\footnotetext{
${ }^{43}$ The last decennial Census to report quarter of birth.
} 
presumably non-Muslims based on reported ancestry and found no effects of similar magnitudes.

To summarize, in the US Census we find: 1) strong evidence of elevated rates of disability from in utero exposure to Ramadan generally toward the middle of pregnancy; 2) evidence of lower earnings with Ramadan exposure early in pregnancy (e.g., first trimester); and 3) suggestive evidence linking Ramadan exposure early in pregnancy to a lower likelihood of completing high school.

\section{Discussion and Future Research}

\subsection{How does fasting observance affect our estimates?}

As rates of fasting by pregnant women during Ramadan approach unity, our ITT estimate approaches the treatment effect of fasting (which cannot be said of previous comparisons between fasters and non-fasters). Fasting observance may be highest in early pregnancy, both because mothers may be unaware they are pregnant and the burden of pregnancy is lower. ${ }^{44}$ Thus, the estimated health damage attributable to Ramadan falling in the first month of pregnancy may approximate the treatment effect of fasting during this period. Correspondence between our ITT estimate and fasting's effect is likely higher in Iraq and Uganda where we have little classification error in Muslim status. In our Michigan data, our proxy for Muslims will include a higher fraction of non-Muslims due to the likely presence of Chaldeans who report Arab ancestry. This is also likely to be the case, albeit to a lesser extent, with our US Census data where we may include some non-Muslim immigrants from predominantly Muslim countries. As compliance (fasting during Ramadan) is presumably zero for non-Muslims, our US ITT estimates are likely attenuated.

Ideally, we would observe fasting behavior by month of pregnancy and subsequent health or human capital outcomes for a large sample of Muslims. With this information

\footnotetext{
${ }^{44}$ The only study that we are aware of that documented differences in fasting behavior across pregnancy was by Arab and Nasrollahi [2001] who found that of the 4,343 women delivering in hospitals in Hamadan, Iran in 1999, fasting was only slightly more common when Ramadan fell in the first trimester $(77 \%$ ) than in the second trimester $(72 \%)$ or third trimester $(65 \%)$.
} 
and a sufficiently long span of birth years, we could construct Wald estimates of the effect of fasting on health during each pregnancy month. Ramadan's coincidence with pregnancy month would be the binary instrumental variable for fasting observance. As long as Muslims are not fasting for other reasons during the month of Ramadan (as seems reasonable), this Wald estimate could be interpreted as the effect of fasting on fasters (i.e., the treatment on the treated rather than simply a $L A T E$ estimate, see Angrist and Pischke [2009]). Failing this, data on fasting behavior and pregnancy month could be used to estimate the first stage effects of Ramadan timing (preferably for the US, Uganda, or Iraq), and combined with our ITT estimates in a two-sample IV procedure. This approach would also integrate potential heterogeneity in fasting rates by pregnancy month.

The most compelling previous studies of the developmental origins of health and disease have relied on exogenous shocks "caused by conditions outside the control of the mother" [Currie, 2009]. These shocks have also typically involved relatively uncommon and severe historical events and so the relevance to policy may be somewhat tenuous. Our study departs from these in considering a treatment that to a greater degree is within the control of the mother (but still identified by exogenous timing) and may potentially be amenable to interventions. We also study a phenomenon that conforms more closely to the established theories relating a decline in circulating levels of maternal glucose during critical windows of embryonic and fetal development. That obtaining a dispensation to postpone fasting until after pregnancy is apparently the exception rather than the norm (see Appendix A.1.2) suggests two possibilities. First, the cost of requesting the dispensation may be high - in part because mothers usually become aware of their pregnancies after the first month [Floyd et al., 1999]. Alternatively, it may be that the full health consequences of Ramadan fasting during pregnancy are unknown. This explanation also seems plausible as ours is the first study to find long-term effects.

An alternative approach families could adopt is to time pregnancies to commence shortly after Ramadan, and thereby avoid the overlap. That we do not observe this behavior could suggest that timing pregnancies is costly or unreliable, ${ }^{45}$ or again that fasting during pregnancy is not considered teratogenic.

\footnotetext{
${ }^{45}$ Dickert-Conlin and Chandra [1999] found a responsiveness to tax incentives in the timing of deliveries, not conceptions.
} 


\subsection{Synthesizing the Results}

In table A1 we present hypotheses concerning which outcomes are likely to be affected by fasting, and in which months of pregnancy. In accordance with our hypotheses, we find evidence that fasting affects birth weight, gestation length and the sex composition at birth using natality data from Michigan. For birth weight it appears that fasting during the first month or two is consistently associated with lower birthweight. However, when we limit our sample full-term births in non-Chaldean zipcodes, we find negative effects in other stages of pregnancy. Our results on the sex composition of births are also consistent with the hypothesis that nutrition shortly after conception matters.

We take these findings primarily as confirmation that there is a detectable effect of fasting that is evident at birth. The absence of such evidence would make the case for long-term effects superficially more suspect but still plausible from the point of view of biological theory. Although some may interpret evidence of negative effects on birth weight as an important finding in and of itself, we take the more conservative view that it merely demonstrates the potential importance of nutritional disruptions during fetal development on long-term outcomes.

Our literature review further suggests that irrespective of when in pregnancy fasting may affect birth outcomes, adult outcomes are generally likely to be affected by prenatal nutritional disruptions early in pregnancy. ${ }^{46}$ Accordingly, we find large effects on disability from early exposure in Uganda and Iraq. In the US, where we have much more blunt data on birth timing, we find that rates of disability are elevated by a very similar magnitude as in Iraq and Uganda but that the timing of effects is now concentrated during the second trimester, though we cannot rule out the possibility of large effects early in pregnancy and find evidence of this when we use only the 1980 US Census (the last decennial Census to report birth quarter).

With respect to education, although we find no evidence of a negative effect in Uganda we do estimate a significantly lower likelihood of completing high school that is associated with early exposure in the US. We note that theory is not clear on whether reductions in health capital in the context of a developing country should reduce schooling since it

\footnotetext{
${ }^{46}$ Evidence from the 1918 and 1957 influenza pandemics suggests that the first half of pregnancy is particularly important to subsequent health and human capital [Almond, 2006, Kelly, 2009].
} 
may also reduce productivity among child laborers. For Uganda, we also find evidence that is consistent with the possibility that sex-specific selective mortality may have led to a positive association. It would be useful for future research to use administrative educational data (e.g. test scores) to more directly ascertain whether there are effects on human capital during adolescence.

Finally, with respect to economic outcomes, we find that fasting early in pregnancy is associated with lower wealth using home ownership in Uganda and home ownership and polygyny in Iraq. In the US we similarly find that early exposure is associated with reduced earnings, although effects are also apparent in other periods of pregnancy.

\subsection{Generalizability and Future Research}

An important caveat of our analysis is that we only measure the reduced form effect of exposure to all aspects of Ramadan's occurrence, not just fasting. The fact that Ramadan may alter other behaviors (e.g. sleeping patterns) may lead one to question whether the effects of fasting during Ramadan generalizes to other contexts such as dieting during pregnancy. We would first emphasize that there is a strong physiologic and empirical basis in the medical literature for expecting that maternal fasting can lead to metabolic changes in the intra-uterine environment (i.e. reductions in glucose and increases in ketones) that could potentially result in adverse birth outcomes. Further, no other behavioral aspect of Ramadan observance that we are aware of has been linked to adverse pregnancy or birth outcomes. Therefore, the fact that accelerated starvation has in fact been documented in both developed and developing countries during Ramadan provides a priori evidence that Ramadan is of direct relevance for understanding the implications of nutritional deprivation during pregnancy more generally. The presence of elevated levels of cortisol provides further evidence of a likely effect. At a minimum, the results of this paper are a clarion call for further research. It would be fruitful for future studies to analyze the extent to which other behavioral aspects of Ramadan may interact with fasting behavior and whether these other factors may serve to amplify or dampen the effects of restricted prenatal nutrition. Finally, setting aside the issue of generalizability, the fact that millions of pregnant Muslim women will fast each year implies that understanding the long-term 
impacts of Ramadan is an important question per se.

Future research should also confirm whether other commonly-experienced disruptions to prenatal nutrition exert similar effects as Ramadan fasting. Most US pregnancies are not recognized until after the first month of gestation [Floyd et al., 1999]. Given the results of this study, maternal behavior particularly during the first month of pregnancy, can have permanent impacts on offspring health. Roughly $40 \%$ of US women of childbearing age are attempting to lose weight [Cohen and Kim, 2009] and $24 \%$ of women reported mealskipping during pregnancy [Siega-Riz et al., 2001]. ${ }^{47}$ Even in relatively well-nourished populations, prenatal nutrition (and at a minimum its timing) may be sub-optimal for fetal development. Future research should employ new identification strategies to evaluate both short and long-term health effects of nutrition in early pregnancy on health and other end points, e.g., test scores.

\footnotetext{
${ }^{47}$ Furthermore, approximately $5 \%$ of pregnant women manifest eating disorders [Turton et al., 1999].
} 


\section{References}

Douglas Almond. Is the 1918 influenza pandemic over? long-term effects of in utero influenza exposure in the post-1940 U.S. population. Journal of Political Economy, 114 (4):672-712, August 2006.

Douglas Almond, Kenneth Y. Chay, and David S. Lee. The costs of low birth weight. The Quarterly Journal of Economics, 120(3):1031-1084, August 2005.

Douglas Almond, Lena Edlund, Michael Joffe, and Mårten Palme. Is hyperemesis gravidarum an adaptive condition? manuscript, Stockholm University, February 2009.

Joshua D. Angrist and Jörn-Steffen Pischke. Mostly Harmless Econometrics: An Empiricist's Companion. Princeton University Press, Princeton, New Jersey, 2009.

Malihe Arab and Shahla Nasrollahi. Interrelation of ramadan fasting and birth weight. Medical Journal of the Islamic Academy of Sciences, 14(3):91-95, 2001.

Fereidoun Azizi, Hossein Sadeghipour, Behnam Siahkolah, and Nasrollah Rezaei-Ghaleh. Intellectual development of children born to mothers who fasted during pregnancy. International Journal of Vitamin and Nutrition Research, 74(5):374-380, September 2004 .

Kasey Buckles and Daniel M. Hungerman. Season of birth and later outcomes: Old questions, new answers. manuscript, University of Notre Dame, July 2008.

Elissa Z. Cameron. Facultative adjustment of mammalian sex ratios in support fo the trivers-willard hypothesis: evidence for a mechanism. Proceedings of the Royal Society B: Biological Sciences, 271(1549):1723-1728, 2004.

Jennifer H. Cohen and Hyoshin Kim. Sociodemographic and health characteristics associated with attempting weight loss during pregnancy. Preventing Chronic Disease: Public Health Research, Practice, and Policy, 6(1):1-9, January 2009. Centers for Disease Control and Prevention.

Dora L. Costa, Lorens A. Helmchen, and Sven Wilson. Race, infection, and arteriosclerosis in the past. Proceedings of the National Academy of Sciences, 104(33):13219-13224, 2007.

Dora L. Costa and Joanna N. Lahey. Predicting older age mortality trends. Journal of the European Economic Association, 3(2-3):487-493, April-May 2005.

Flavio Cunha and James J. Heckman. The technolgy of skill formation. American Economic Review, 97(2):31-47, May 2007.

Janet Currie. Healthy, wealthy, and wise: Is there a causal relationship between child health and human capital development? Journal of Economic Literature, XLVII(1): 87-122, March 2009.

Angus Deaton, Carlos Bozzoli, and Climent Quintana-Domeque. Child mortality and adult height. Demography, forthcoming 2009. 
Stacy Dickert-Conlin and Amitabh Chandra. Taxes and the timing of births. Journal of Political Economy, 1999, vol. 107, no. 1, 107(1):161-177, 1999.

E. Dikensoy, O. Balat, B. Cebesoy, A. Ozkur, H. Cicek, and G. Can. The effect of Ramadan fasting on maternal serum lipids, cortisol levels and fetal development. Archives of gynecology and obstetrics, 279(2):119, 2009.

Gabriele Doblhammer and James W. Vaupel. Lifespan depends on month of birth. Proceedings of the National Academy of Sciences, 98(5):2934-2939, February 2001.

Lena Edlund. Son preference, sex ratios, and marriage patterns. Journal of Political Economy, 107(6):1275-1304, December 1999.

John L. Esposito. The Oxford Dictionary of Islam. Oxford University Press, Oxford, 2003.

Reyn Van Ewijk. Long-term health effects on the next generation of ramadan fasting during pregnancy. April 2009. CEP Discussion Paper No 926.

RL Floyd, P Decoufle, and DW Hungerford. Alcohol use prior to pregnancy recognition. American Journal of Preventive Medicine, 17:101-107(7), August 1999.

Kathryn L. Franko, Peter D. Gluckman, Catherine M. Law, Alan S. Beedle, and Susan M.B. Morton. Small for Gestational Age. Causes and Consequences, volume 13 of Pediatr Adolesc Med., chapter Low Birth Weight and Optimal Fetal Development: A Global Perspective, pages 73-85. Karger, Basel, 2009. W Kiess W and SD Chernausek SD and ACS Hokken-Koelega: (editors).

GAO. The american community survey: Accuracy and timeliness issues. Technical report, The General Accounting Office, Washington, DC, September 2002. GAO-02-956R.

Peter Gluckman and Mark Hanson. The Fetal Matrix: Evolution, Development and Disease. Cambridge University Press, Cambride, England, 2005.

ES Hunter and TW Sadler. D-(-)-beta hydroxybutyrate-induced effects on mouse embryos in vitro. Teratology, 36:259-64, 1987.

Amita Kapoor, Elizabeth Dunn, Alice Kostaki, Marcus H. Andrews, and Stephen G. Matthews. Fetal programming of hypothalamo-pituitary-adrenal function: Prenatal stress and glucocorticoids. Journal of Physiology, 572(1):31-44, 2006.

Zohreh Kavehmanesh and Hassan Abolghasemi. Maternal ramadan fasting and neonatal health. Journal of Perinatology, 24:748-750, 2004.

Elaine Kelly. The scourge of asian flu: in utero exposure to pandemic influenza and the development of a cohort of british children. IFS Working Paper, September 2009.

Sebastian Kraemer. The fragile male. BMJ, 321(7276):1609-1612, 2000. 
Ashok Malhotra, P.H. Scott, J.S. Scott, H. Gee, and B.A. Wharton. Metabolic changes in asian muslim pregnant mothers observing the ramadan fast in britian. British Journal of Nutrition, 61(3):663-672, May 1989.

Fiona Mathews, Paul J. Johnson, and Andrew Neil. You are what your mother eats: evidence for maternal preconception diet influencing foetal sex in humans. Proceedings of the Royal Society B, pages 1-8, April 2008.

P. J. Meis and J.C. Roseand M. Swain. Pregnancy alters diurnal variation of plasma glucose concentration. Chronobiol. Int., 1:145-149, 1984.

Boyd E. Metzger, Veronica Ravnikar, Rita A. Vileisis, and Norbert Freinkel. 'accelerated starvation' and the skipped breakfast in late normal pregnancy. The Lancet, 1(8272): 588-592, March 1982.

Hisham M. Mirghani, Sarath Weerasinghe, Shamsaa Al-Awar, Lolowa Abdulla, and Mutairu Ezimokhai. The effect of intermittent maternal fasting on computerized fetal heart tracing. Journal of Perinatology, 25:90-92, 2005.

H.M. Mirghani, S.D. Weerasinghe, J.R. Smith, and M. Ezimokhai. The effect of intermittent maternal fasting on human fetal breathing movements. Journal of Obstetrics and Gynaecology, 24(6):635-637, September 2004.

DCP Moore, M Stanisstreet, and CA Clarke. Morphological and physiological effects of beta-hydroxybutyrate on rat embryos grown in vitro at different stages. Teratology, 40: 237-51, 1989.

Institute of Medicine, editor. Nutrition During Pregnancy and Lactation: An Implementation Guide. National Academy Press, Washington D.C., 1992.

M Pearl, ML Wier, and M Kharrazi. Assessing the quality of last menstrual period date on california birth records. Paediatric and perinatal epidemiology, 21 Suppl 2:50, 2007.

AM Prentice, A Prentice, WH Lamb, PG Lunn, and S. Austin. Metabolic consequences of fasting during ramadan in pregnant and lactating women. Human nutrition. Clinical nutrition, 37(4):283-94, July 1983.

T Rizzo, BE Metzger, WJ Burns, and K Burns. Correlations between antepartum maternal metabolism and child intelligence. New England Journal of Medicine, 325:911-916, 1991.

Laura A. Schieve, Geraldine S. Perry, Mary E. Cogswell, Kelley S. Scanlon, Deborah Rosenberg, Suzan Carmichael, and Cynthia Ferre. Validity of self-reported pregnancy delivery weight. American Journal of Epidemiology, 150(9), 1999.

WHD Scotland. Length of gestation of east african women. Journal of Obstetrics and Gynaecology, 63(1):120-123, 1956.

EA Sheehan, F Beck, CA Clarke, and M Stanisstreet. Effects of beta-hydroxybutyrate on rat embryos grown in culture. Experentia, 41:273-75, 1985. 
Anna Maria Siega-Riz, Tracy Hermann, David A Savitz, and John M Thorp. Frequency of eating during pregnancy and its effect on preterm delivery. American Journal of Epidemiology, 153(7):647-652, 2001.

P. Turton, P. Hughes, H. Bolton, and P. Sedgwick. Incidence and demographic correlates of eating disorder symptoms in a pregnant population. The International Journal of Eating Disorders, 26(4):448-452, 1999. 


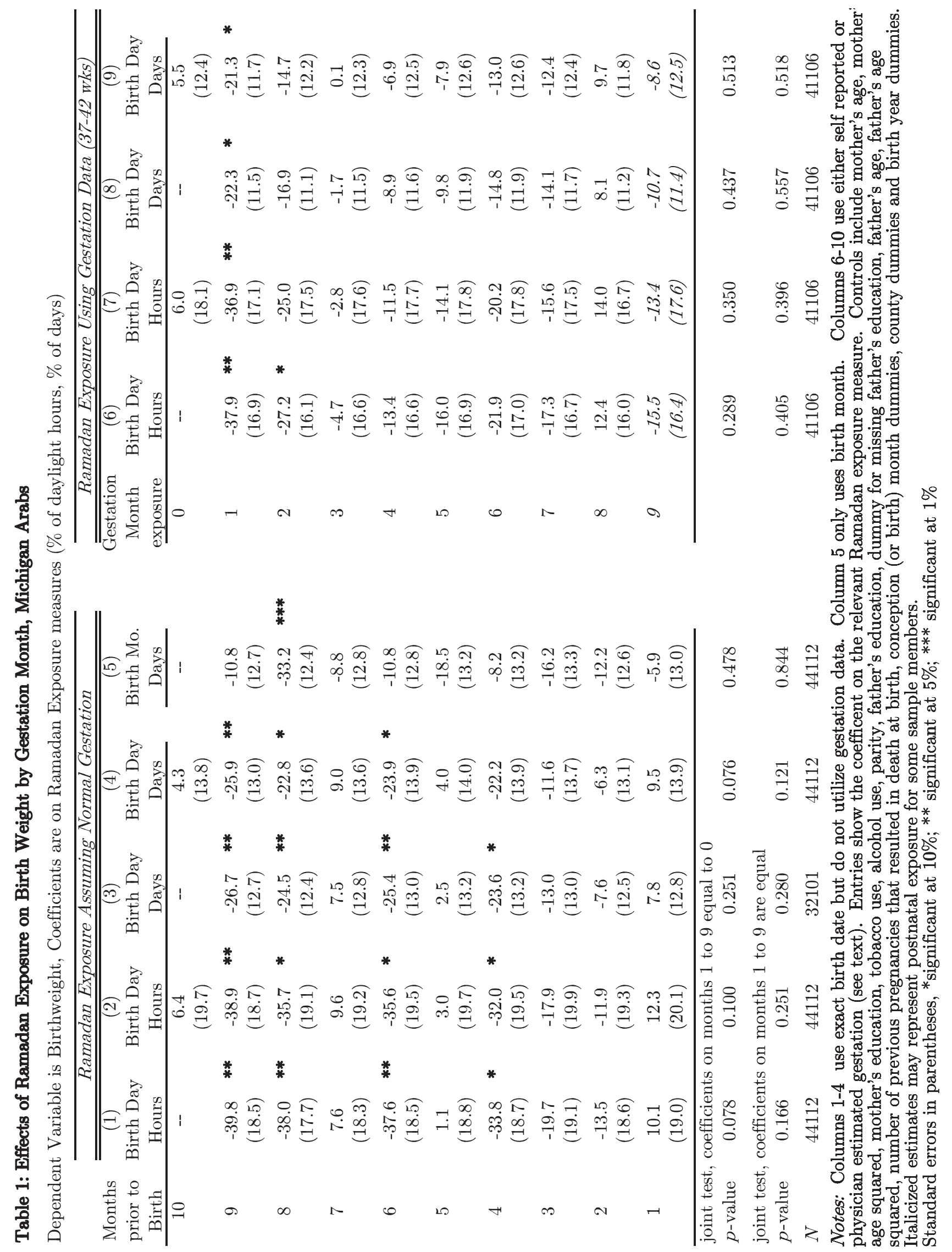



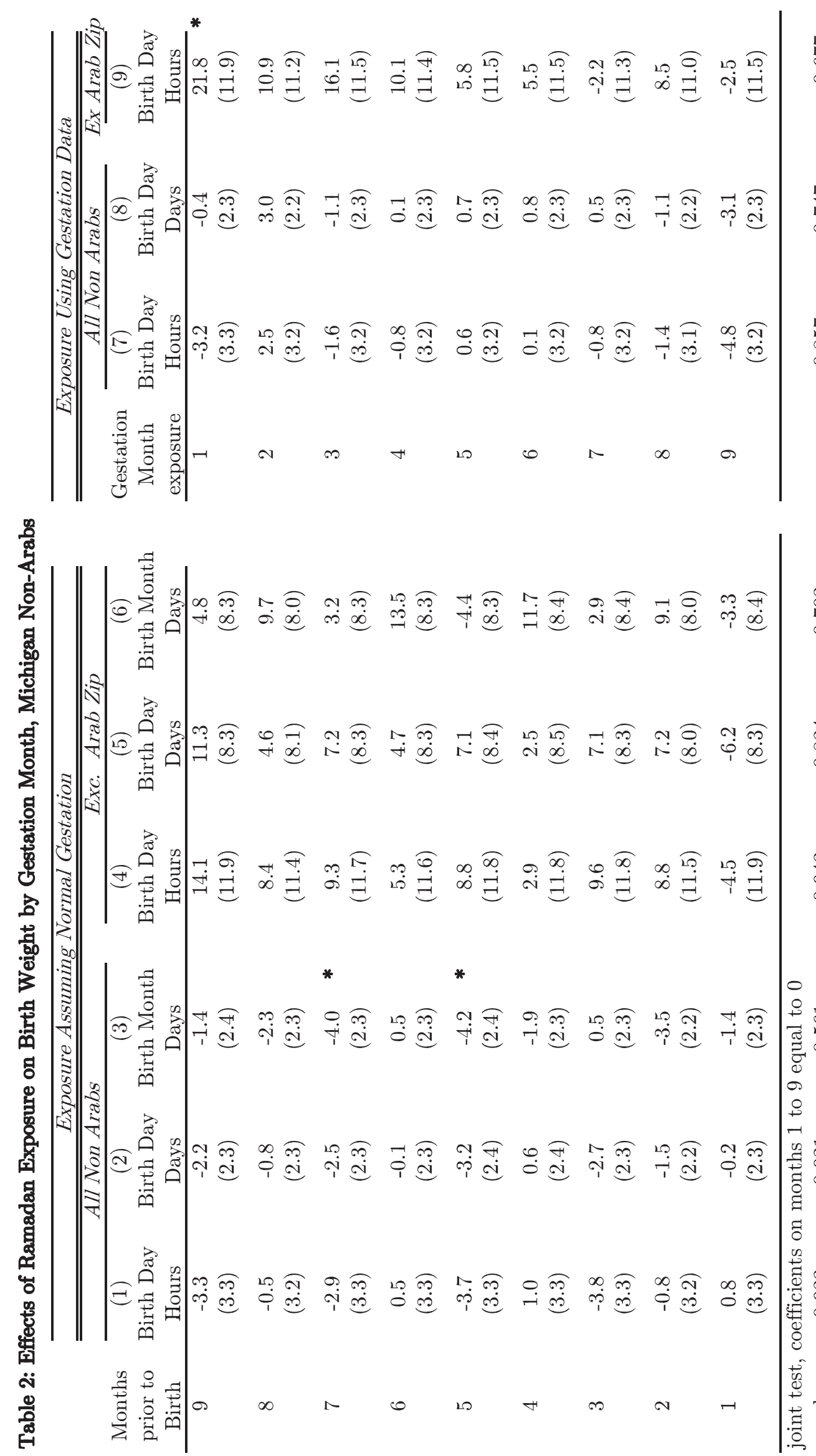


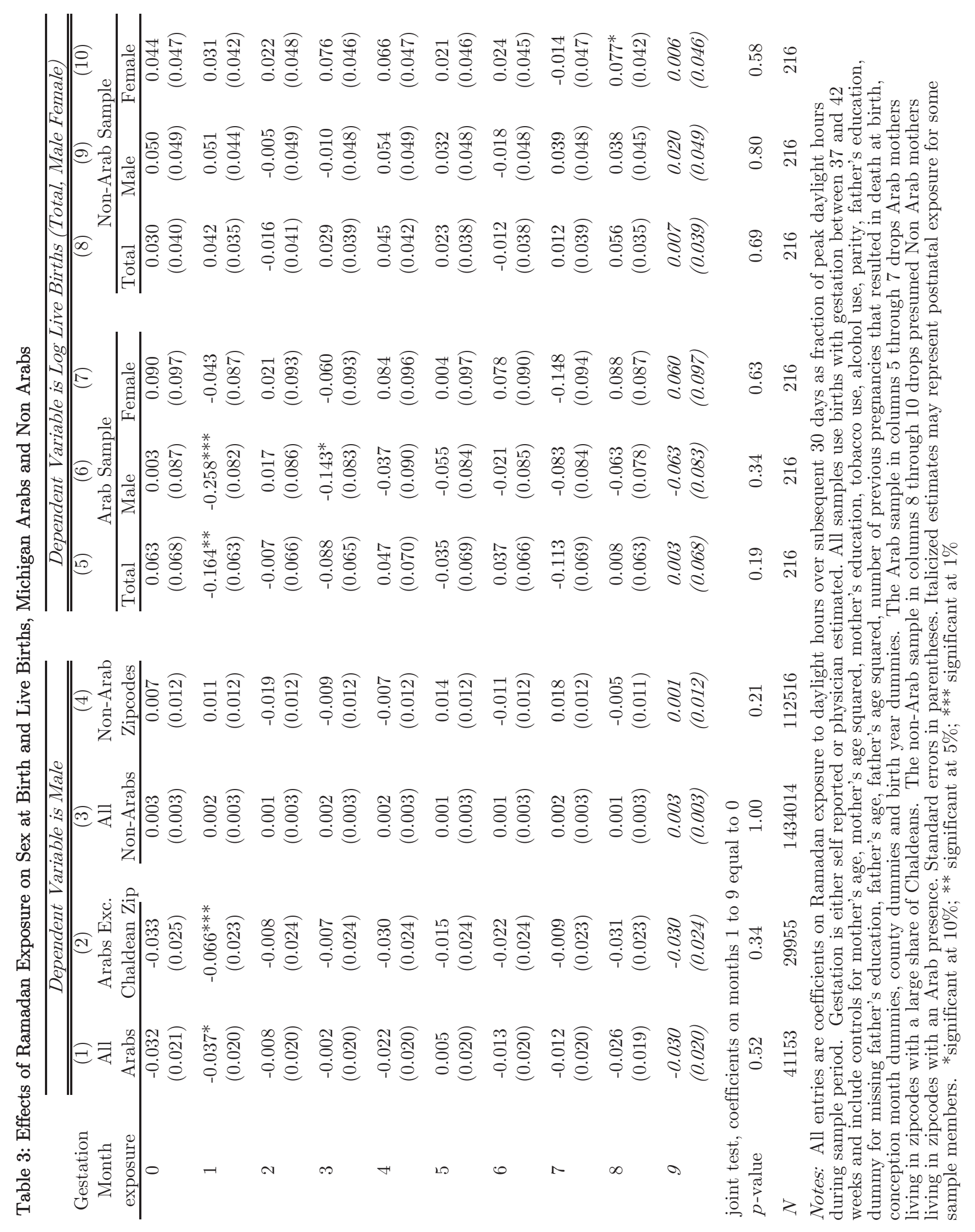




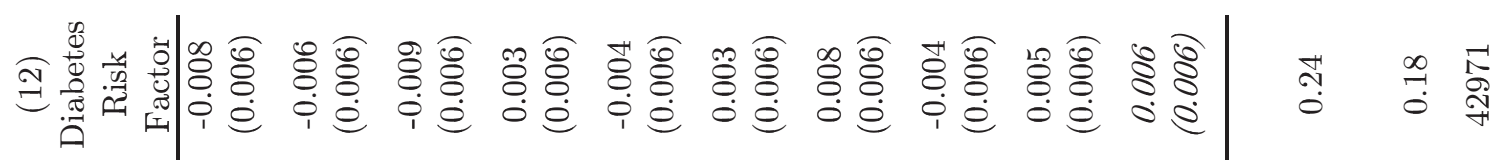

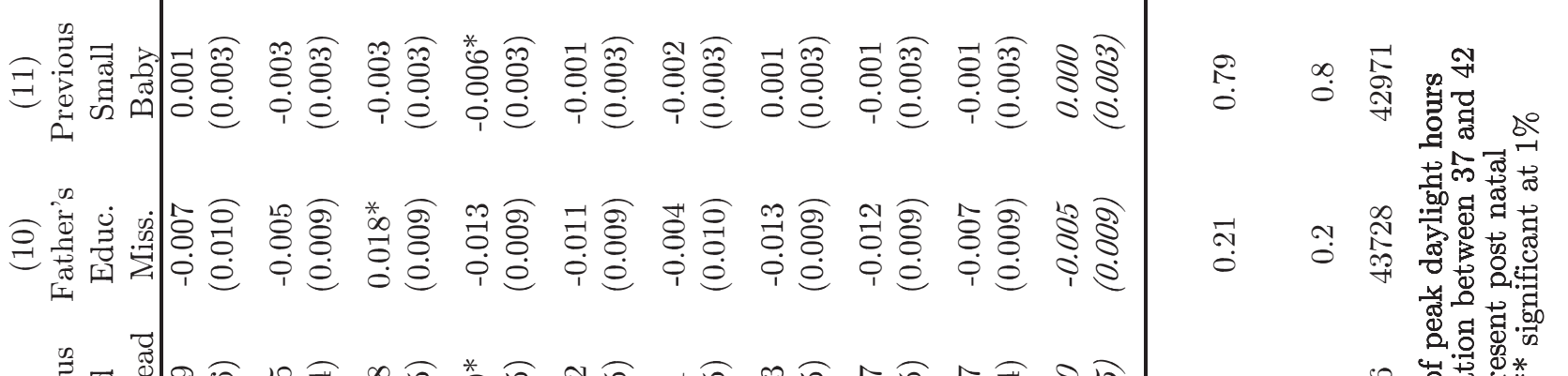

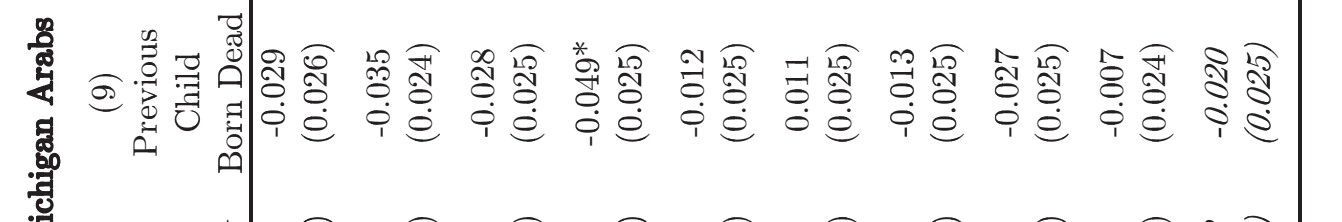

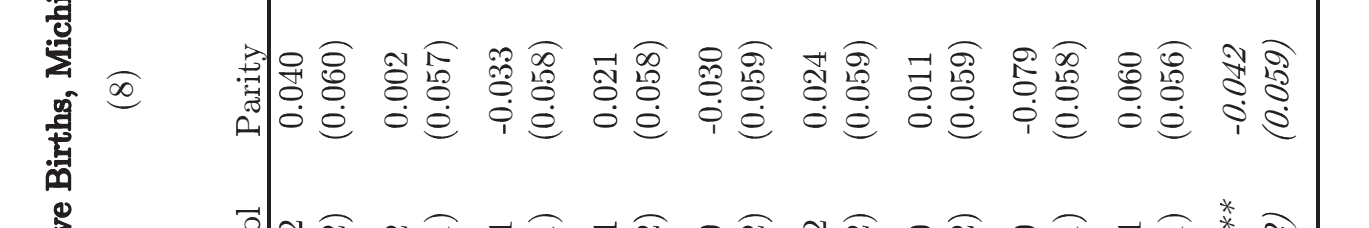

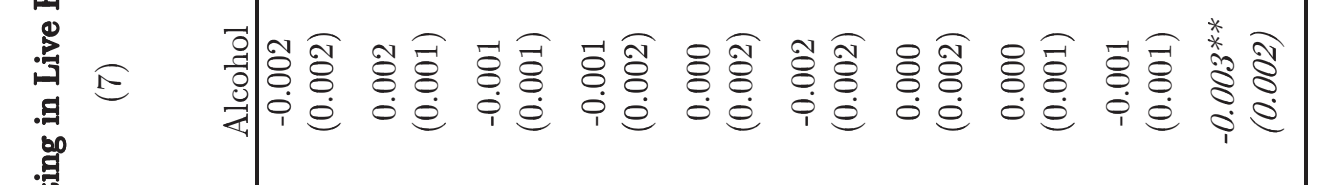

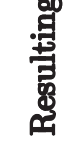

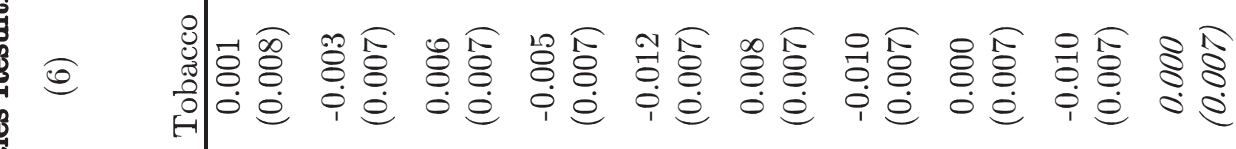

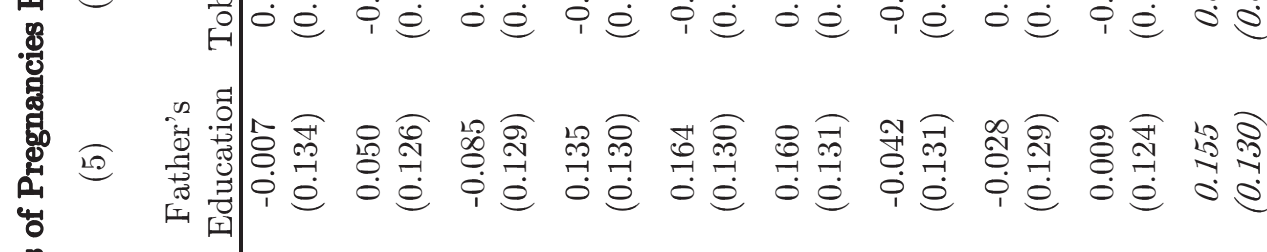

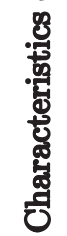

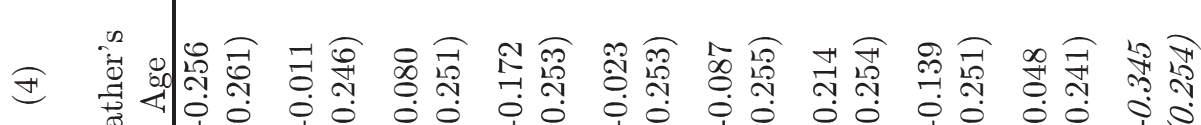

二

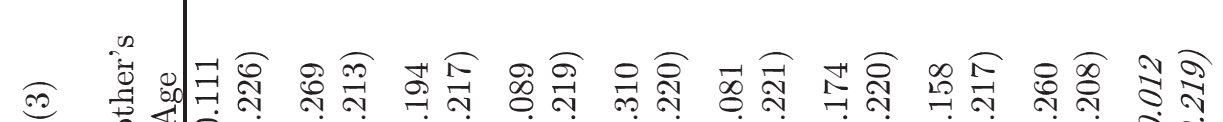

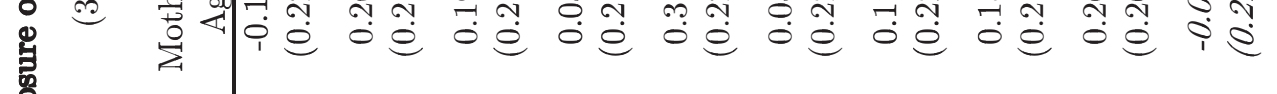

.

ฐ

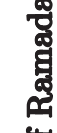

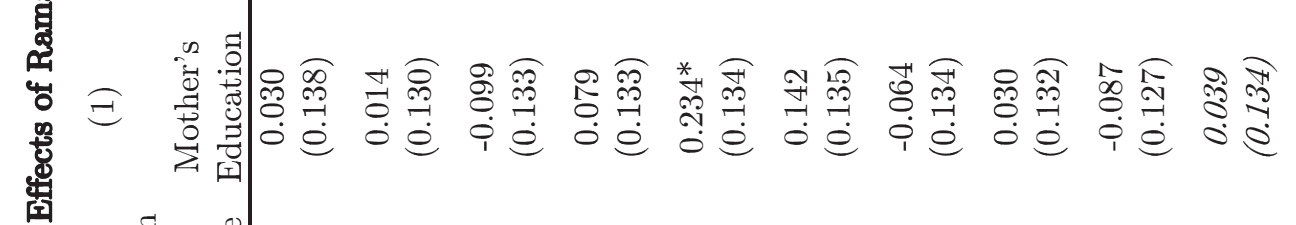




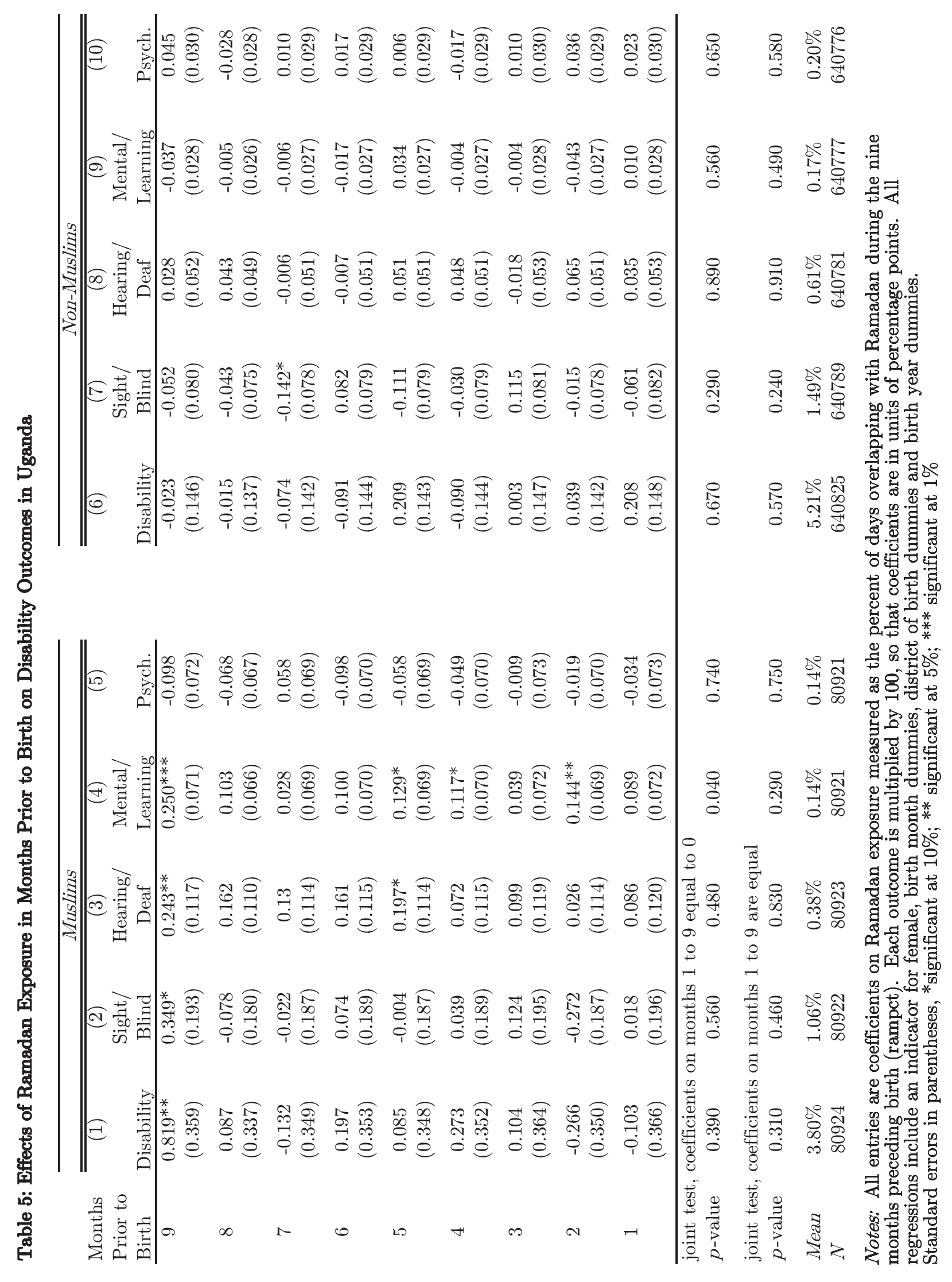




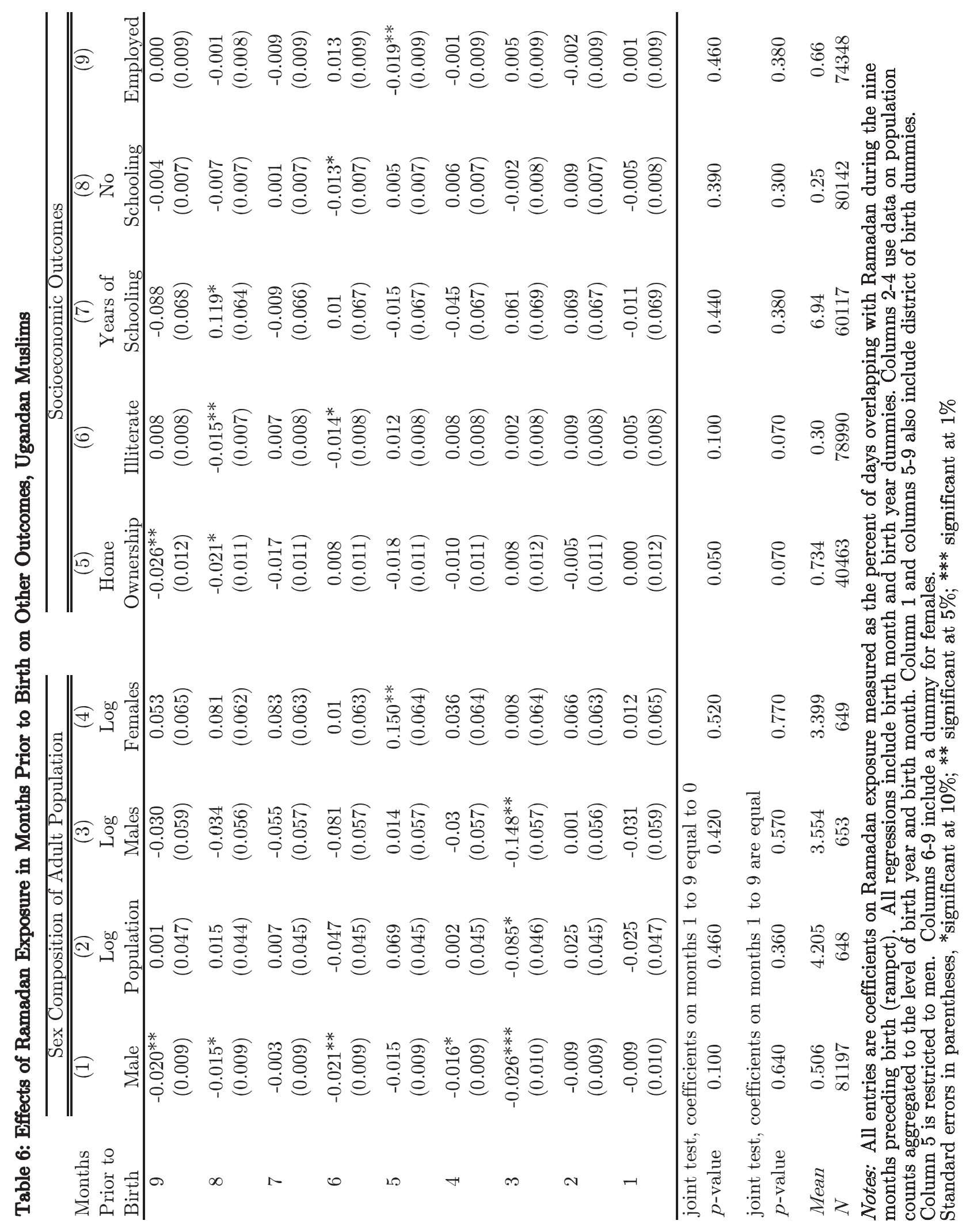




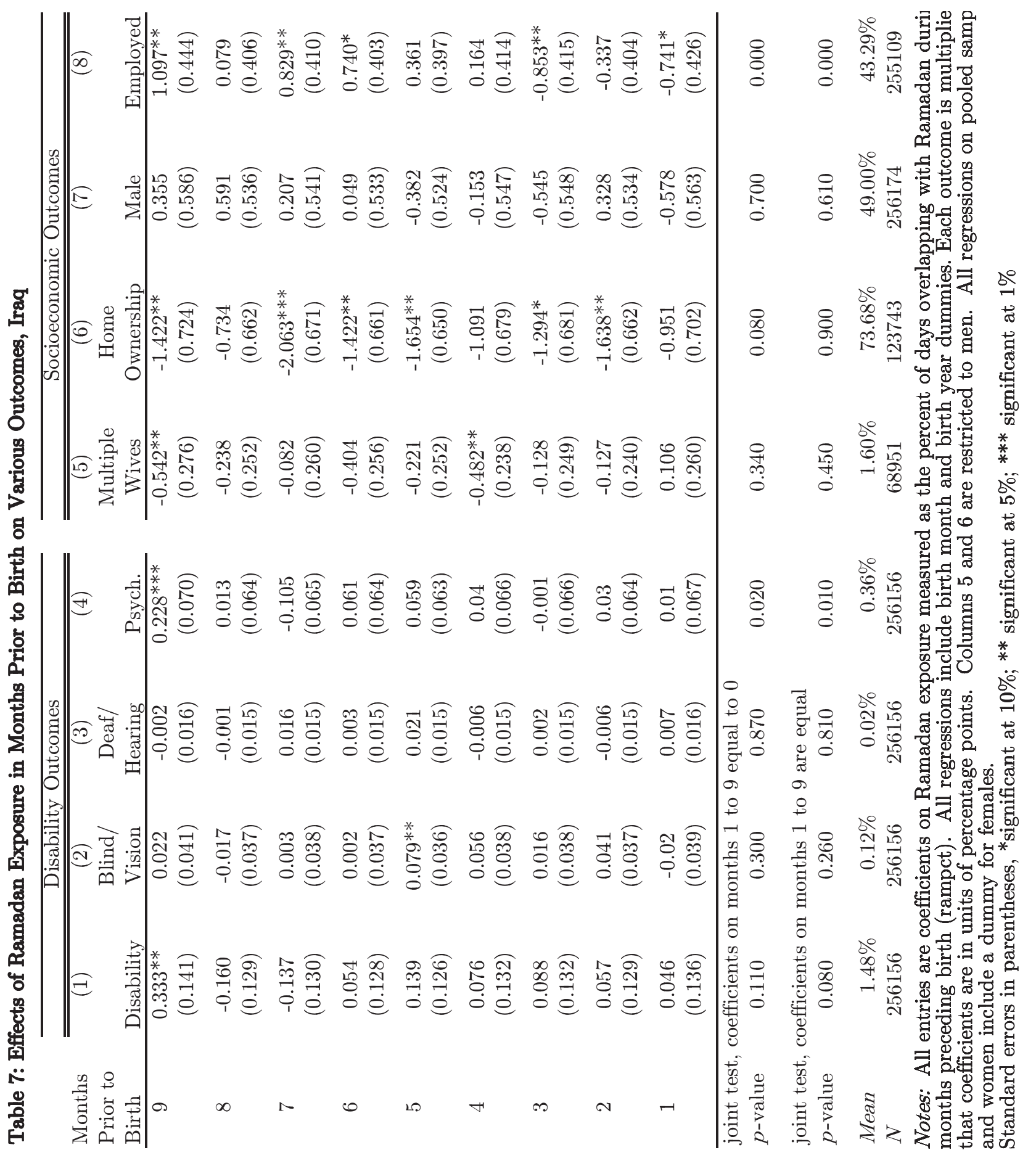




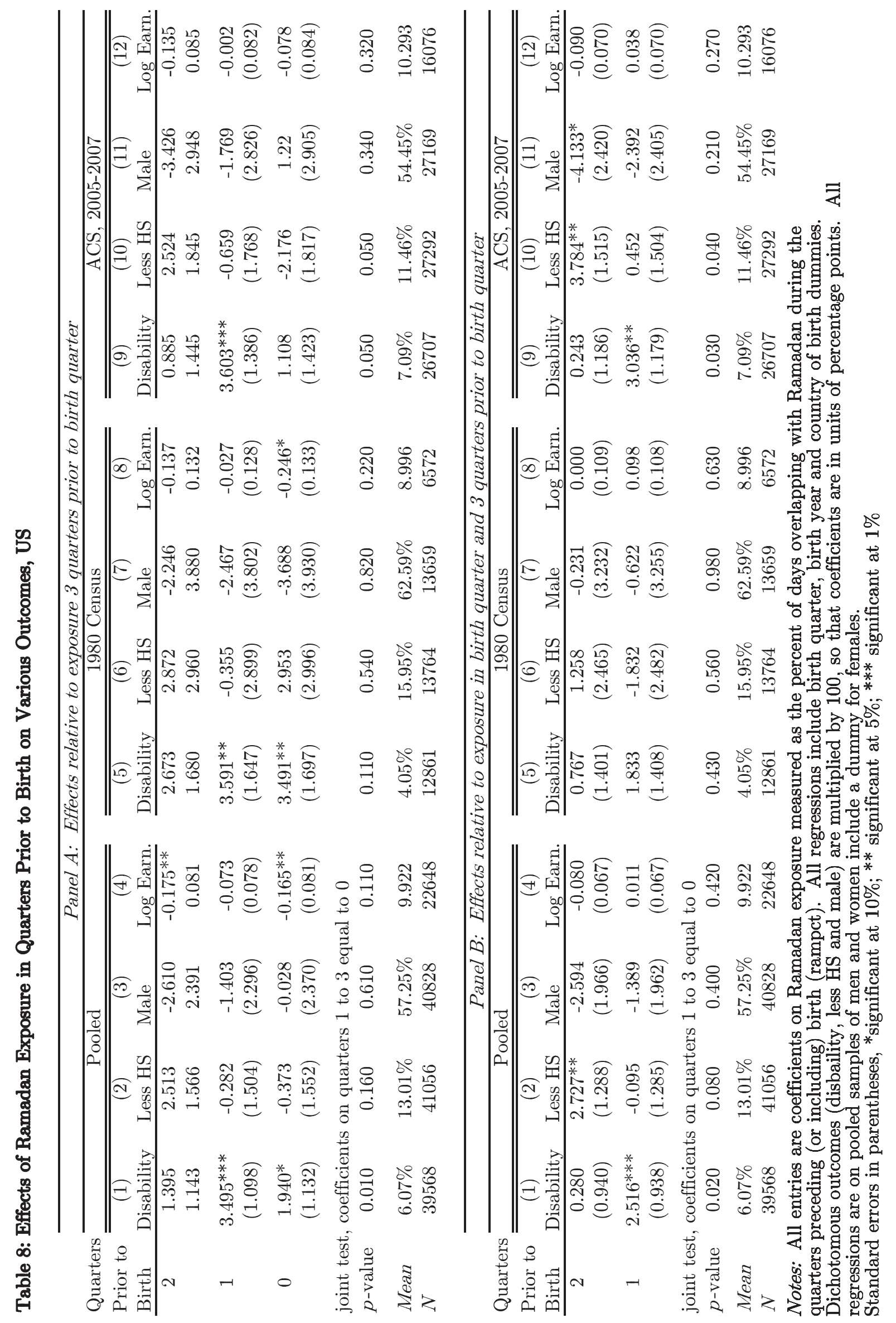




\section{Contents}

A Biomedical Studies of Fasting ii

A.1 First Stage Effects of Ramadan . . . . . . . . . . . . . . . . . . ii

A.1.1 Caloric Intake and Weight Among Fasting Adults . . . . . . . . . . ii

A.1.2 Is Ramadan Observed by Pregnant Muslims? . . . . . . . . . . . . iii

A.2 Ramadan and Fetal Health . . . . . . . . . . . . . . . . . . . iv

A.2.1 Pathways from Maternal to Fetal Health . . . . . . . . . . . iv

A.2.2 Empirical Studies of Fetal Health . . . . . . . . . . . . . v

A.3 Mechanisms of Fetal Programming . . . . . . . . . . . . . . . . v v

A.4 Ramadan and Perinatal Health . . . . . . . . . . . . . . . . . . vii

A.4.1 Birth Outcomes . . . . . . . . . . . . . . vii

A.4.2 Longer-term Effects . . . . . . . . . . . . . . . . . . viii

A.5 Nutrition and the Sex Ratio at Birth . . . . . . . . . . . . . . . . viii

A.6 Hypotheses: Outcomes and Timing . . . . . . . . . . . . . . . x

B Data $\quad$ X

B.1 Michigan Natality Microdata . . . . . . . . . . . . . . x

B.2 Uganda Census $2002 \ldots \ldots$. . . . . . . . . . . . . . . xii

B.3 Iraq Census $1997 \ldots \ldots$. . . . . . . . . . . . . . . xiii

B.4 US Census 1980, ACS, 2005-2007 . . . . . . . . . . . . . xiii

B.5 Other Suitable Datasets? . . . . . . . . . . . . . . . . xiv

C Birth Outcomes by Gestation Length xiv

D Distributional Effects on Birth Weight xvi

\section{E Appendix Tables \& Figures}

Tables A1-A7, Figures A1-A4 


\section{A Biomedical Studies of Fasting}

We begin by summarizing evidence on the "first stage" effect of fasting during Ramadan. That is, what is the existing evidence that Ramadan fasting can have a detectable effect on health? In Section A.1, we consider studies of caloric intake and weight change during intermittent fasting and summarize survey data on the prevalence of Ramadan fasting among pregnant women. Second, we discuss the potential impacts of maternal biochemical changes caused by fasting (accelerated starvation) on the fetus in Section A.2. Third, we examine potential pathways by which intermittent fasting could have lasting effects through "fetal programming" in Section A.3. Fourth, we review the empirical studies that have explicitly examined the effects of Ramadan on birth and early childhood outcomes in Section A.4. Fifth, we briefly summarize a separate literature on nutrition and the sex ratio at birth - which to date has not used Ramadan fasting for identification - in Section A.5 . Finally, we distill the preceding into research hypotheses which we will apply to our data in Section A.6.

\section{A.1 First Stage Effects of Ramadan}

\section{A.1.1 Caloric Intake and Weight Among Fasting Adults}

Ramadan fasting in the adult population (i.e. not conditioning on pregnancy) has been associated with modest but statistically significant declines in the weight of fasters of around 1 to $3 \mathrm{~kg}$ (Husain et al. [1987]; Ramadan et al. [1999]; Adlouni et al. [1998]; Mansi [2007]; Takruri [1989]) Reductions in weight are sometimes (but not always) accompanied by declines in caloric intake and likely depend on dietary customs in specific countries. ${ }^{1}$

Two studies are of particular relevance. First, in a study of 185 pregnant women, Arab [2003] found that over a 24 hour period encompassing the Ramadan fast, over 90 percent of the women had a deficiency of over 500 calories relative to the required energy intake and 68 percent had a deficiency of over 1000 calories. Second, in the only large scale population-based study we are aware of, Cole [1993] found striking evidence of sharp weight changes during Ramadan for women in Gambia. The study was notable because it used fixed effects with 11 years of panel data and controlled for calendar month, calendar year, and stage of pregnancy (or lactation). Appendnix Figure A1, taken from the study, shows that relative to the rest of the year, there is an increase in weight during the four

\footnotetext{
${ }^{1}$ For example, Husain et al. [1987] found reductions in caloric intake of between 6 percent and 25 percent relative to nonfasting conditions among Malaysians. In contrast, Adlouni et al. [1998] found a 20 percent increase in calories per day among Moroccans.
} 
weeks prior to Ramadan and a sharp increase in weight at the very beginning of Ramadan. This is followed by an abrupt fall in weight of over $1 \mathrm{~kg}$ ( 2.2 pounds) during the subsequent 3 weeks of fasting. The figure provides striking visual evidence that daytime fasting during Ramadan is affecting weight gain.

In any case, as we discuss in section 2.1 of the paper, fasting may induce maternal biochemical changes and reprogramming of the neuro-endocrine system due to alterations in the the timing of nutritional intake even if overall caloric intake or weight change is unaffected.

\section{A.1.2 Is Ramadan Observed by Pregnant Muslims?}

Although pregnant women may request an exemption from fasting, they are expected to "make up" the fasting days missed during pregnancy after delivery and this requirement may discourage pregnant women from seeking the exemption since they may be the only member of the household fasting [Hoskins, 1992, Mirghani et al., 2004]. ${ }^{2}$ Mirghani et al. [2004] noted: "Most opt to fast with their families rather than doing this later":636. In addition, some Muslims interpret Islamic Law as requiring pregnant women to fast. For example, the religious leader of Singapore's Muslims held that: "a pregnant woman who is in good health, capable of fasting and does not feel any worry about herself or to her foetus, is required and expected to fast like any ordinary woman" [Joosoph and $\mathrm{Yu}, 2004] .^{3}$ Furthermore, since fasting during Ramadan is one of the five pillars of Islam and is a central part of the culture of the Muslim community, many women fear a loss of connection with the community or would feel guilty about not observing Ramadan [Robinson and Raisler, 2005].

As far as we are aware, comprehensive data on Ramadan fasting during pregnancy do not exist. Various surveys of Muslim women suggest that fasting is the norm. For example, of the 4,343 women delivering in hospitals in Hamadan, Iran in 1999, 71\% reported fasting at least 1 day, "highlighting the great desire of Muslim women to keep fasting in Ramadan, the holy month" [Arab and Nasrollahi, 2001]. In a study in Singapore, $87 \%$ of the 181 muslim women surveyed fasted at least 1 day during pregnancy, and $74 \%$ reported completing at least 20 days of fasting [Joosoph and Yu, 2004]. In a study

\footnotetext{
${ }^{2}$ There are some differences in interpretation of the Koran among Imams regarding whether pregnant women must make up the fasting days later or simply pay alms for the poor, or both. See, for example, http://islam1.org/iar/imam/archives/2006/09/09/fasting_the_month_of_ramadaan.php

${ }^{3}$ Similarly, Arab and Nasrollahi [2001] noted that "According the Islamic teaching pregnant women are allowed to fast if it is not harmful to them"; faculty at the Kurdistan Medical Science University in Iran noted that pregnant and breastfeeding women "who fear for the their well being or that of the foetus/child" may be exempted from fasting [Shahgheibi et al., 2005].
} 
conducted in Sana'a City, Yemen, more than 90 percent fasted over 20 days [Makki, 2002]. At the Sorrento Maternity Hospital in Birmingham, England, three quarters of mothers fasted during Ramadan [Eaton and Wharton, 1982]. In a study conducted in Gambia, 90 percent of pregnant women fasted throughout Ramadan [Prentice et al., 1983]. In the US, a study of 32 Muslim women in Michigan found that 28 had fasted in at least one pregnancy and reported that 60-90 percent of women from their communities fast during pregnancy [Robinson and Raisler, 2005].

In summary, survey data indicate that most but not all women observe the Ramadan fast during pregnancy. To the extent that pregnant Muslim women do not fast, ITT estimates are conservative estimates of fasting's effect. As discussed in Section 6 of the main paper, fasting observance is likely highest in early pregnancy.

\section{A.2 Ramadan and Fetal Health}

\section{A.2.1 Pathways from Maternal to Fetal Health}

Does exposure to ketones during "accelerated starvation" (Section 2.1 of the main text) impair the neural development of the fetus? Controlled studies of mice and rats have shown that prenatal exposure to ketones result in impaired neurological development. [Hunter and Sadler, 1987, Moore et al., 1989, Sheehan et al., 1985]. Hunter and Sadler [1987] reference studies showing ketones "rapidly diffuse from the maternal circulation across extraembryonic membranes":263. They also point out that in addition to the period of neurulation (3rd to 4th week of gestation in humans), the earliest stages of embryogenesis when the "primitive streak" is observed (the 13th day post-conception), may be especially susceptible to ketones. Moore et al. [1989] noted that "even a relatively brief episode of ketosis might perturb the development of the early embryo":248. They also emphasize that the effects of ketones were to slow neurological development rather than to produce a malformation. This may explain why similar studies in human populations have not (for the most part) found evidence of congenital malformations [ter Braak et al., 2002]

A related literature has examined the effects of poor metabolic regulation during pregnancy in mothers with Type 1 diabetes. In this case although the primary concern is avoiding hyperglycemia (abnormally high blood glucose), this sometimes results in severe cases of hypocglycemia (abnormally low blood glucose). The latter case may be instructive for understanding the potential effects of accelerated starvation since blood glucose drops after a prolonged fast. Some studies of in utero exposure to hypocglycemia 
among diabetic mothers have shown that fetal growth is reduced and that the key period is between the fourth to sixth weeks of gestation [ter Braak et al., 2002]). It has also been shown that hypoglycemia among non-diabetic mothers is also associated with lower birth weight [Scholl et al., 2001]. Studies of diabetic mothers have shown long-term effects of accelerated starvation on cognitive functioning during childhood (Rizzo et al. [1991], Langan et al. [1991]).

\section{A.2.2 Empirical Studies of Fetal Health}

Fetal health measures have the advantage of permitting panel data techniques to address selection in to maternal fasting but the disadvantage of not being standardized health metrics. Several studies of maternal fasting during Ramadan have found adverse effects on at least two of these fetal health indicators. Mirghani et al. [2004] found evidence of reduced fetal breathing movements where measures of fetal breathing were taken both before and after fasting on the same day. The same study, however, found no change in overall body movements, fetal tone or maternal appreciation. ${ }^{4}$ Mirghani et al. [2005] found a significantly fewer heart rate accelerations among pregnant women who were fasting during Ramadan late in pregnancy compared to controls. This was observed despite relatively short diurnal fasts (less than 10 hours duration) and the absence of significant changes in glucose levels. DiPietro et al. [2007] found a strong association between variation in fetal heart rate in utero and mental and psychomotor development and language ability during early childhood. Finally, Mirghani et al. [2007] found no effect of Ramadan fasting on uterine arterial blood flow.

In contrast, studies of hypoglycemia in animals and humans have examined the fetal heart rate, fetal breathing movements, and limb and body movements in order to identify impairments to fetal development. A review of these studies in ter Braak et al. [2002] do not show much affect of moderate hypoglycemia on fetal conditions.

\section{A.3 Mechanisms of Fetal Programming}

We now discuss how disruptions to fetal health can have permanent effects. In a review of epidemiological studies on the fetal origins of adult diseases, Jaddoe and Witteman [2006] describe two hypotheses related to our study. The first is described as "fetal undernutrition." According to this view, inadequate prenatal nutrition leads to developmental adaptations that are beneficial for short-term survival but lead to lower birth weight.

\footnotetext{
${ }^{4}$ A significant reduction in upper limb movements was noted but there was a concern that this might be due to observer bias.
} 
However, by permanently reprogramming the physiology and metabolism of the fetus, this ultimately makes the body susceptible to heart disease and diabetes during adulthood. ${ }^{5}$ Although most studies of fetal origins have relied on blunt measures such as birth weight to proxy for nutritional restriction during pregnancy, a recurring theme in many studies is that fetal programming may occur even in the absence of birth weight effects. For example, studies of the Dutch famine have showed that those exposed to the famine early in gestation had dramatically higher rates of heart disease but did not have lower birth weight [Painter et al., 2005]. Similarly animal studies have often found evidence of fetal programming without detecting significant changes in fetal weight. e.g. Nishina et al. [2004]

A second prominent hypothesis is that nutritional restrictions inhibit the development of a placental enzyme that is required to convert cortisol into inactive cortisone, thereby exposing the fetus to excessive amounts of cortisol. It is suggested that exposure to glucocorticoids such as cortisol in utero leads to a reprogramming of the hypothalamicpituitary adrenal axis (HPA) which in turn, could lead to impaired fetal development and worse health during adulthood.

In controlled animal studies, researchers have linked nutritional restrictions very early in gestation to an altered neuro-endocrine system, e.g., Nishina et al. [2004]. With respect to humans, Herrmann et al. [2001] have shown an association between fasts of 13 hours or longer and higher levels of plasma corticotrophin-releasing hormone $(\mathrm{CRH})$ which could reflect a reprogramming of the HPA axis. As noted in the main text, Dikensoy et al. [2009] show that Ramadan fasting is associated with elevated cortisol levels during pregnancy (relative to pre-pregnancy levels), but not for non-fasting mothers. Kapoor et al. [2006] describe how the effects of fetal programming of HPA in humans may result in cognitive impairment; due to the complex feedback mechanisms involved, these effects may not be evident "until adulthood or early old age". The authors also emphasize that many of the long-term effects may be sex-specific.

The existing literature on fetal origins however, has made little use of quasi-experimental research designs to address potential confounding factors or to identify the underlying mechanisms. Jaddoe and Witteman [2006] recently concluded: "Thus far, it is still not known which mechanisms underlie the associations between low birth weight and diseases in adult life. The causal pathways linking low birth weight to diseases in later life seem to be complex and may include combined environmental and genetic mechanisms in var-

\footnotetext{
${ }^{5}$ Jaddoe and Witteman [2006] note that this view has evolved into a more "general developmental plasticity model in which various fetal and post-natal environmental factors lead to programming responses":93.
} 
ious periods of life. Well-designed epidemiological studies are necessary to estimate the population effect size and to identify the underlying mechanisms" Jaddoe and Witteman [2006, 91].

\section{A.4 Ramadan and Perinatal Health}

\section{A.4.1 Birth Outcomes}

Existing studies of birth outcomes have relied on comparisons between mothers who reported fasting to those who did not. Kavehmanesh and Abolghasemi [2004] compared 284 births to mothers in Tehran with a "history of fasting during pregnancy" to 255 mothers who did not fast. Although there were no statistically significant differences with respect to maternal education or height, pre-pregnancy BMI's were substantially higher in the fasting group. For such comparisons, the conditional independence assumption required for causal inference [Angrist and Pischke, 2009] is tenuous. Shahgheibi et al. [2005] studied 179 newborns for whom Ramadan fell in the third trimester of pregnancy. Among fasters, birth weight was lower by 33 grams, birth length was lower by about 0.2 centimeters while head circumference was larger by 0.08 centimeters. Since these differences were not statistically significant with the small sample used, the authors concluded that fasting during the third trimester had "no effect" on growth indices. Arab and Nasrollahi [2001] studied 4,343 pregnancies in the Hamdan province of Iran and concluded that fasting did not impact birth weight. They did note however, that the incidence of low birth weight $(<2500$ grams) was higher among fasters in the second trimester but that this was significant only at the 9 percent level.

The largest and perhaps most commonly cited study on the effects of Ramadan on birth weight conducted a retrospective analysis of 13,351 babies born at full term from 1964-84 in Birmingham, England Cross et al. [1990]. Babies were categorized as Muslim on the basis of the first three letters of the mother's surname and were matched to control groups by age. However, this study did not compare the birthweights of Muslims in utero during Ramadan to Muslims who were not in utero during Ramadan but instead compared across groups of Muslims and Non-Muslims. In addition, by design the study did not look at the potential effects of Ramadan on gestation length. Although Cross et al. [1990] found no significant effects on mean birth weight, like Arab and Nasrollahi [2001], they also found a higher incidence of low birth weight among fasters during the second trimester. Opaneye et al. [1990] found that in Al-Kharj, Saudi Arabia, the incidence of low birth weight increased during Islamic festivals, Ramadan in particular. 9.9\% of the 
415 births were below 2,500 grams during Ramadan, versus $6.3 \%$ for the 4,865 births in non-Ramadan months. Finally, Malhotra et al. [1989] and Mirghani and Hamud [2006] found no effects on birthweight and APGAR scores, even though they detected substantial biochemical changes.

A separate literature has found that skipping meals (not associated with Ramadan) has been associated with preterm delivery. Siega-Riz et al. [2001] studied diets during the second trimester of pregnancy for over 2000 women in North Carolina and found that women who did not follow the optimal guidelines of three meals and two snacks a day were 30 percent more likely to deliver preterm. They suggest that this is consistent with experimental evidence from animal studies. Herrmann et al. [2001] also reported that women who fasted for 13 hours or more were three times more likely to deliver preterm.

While most studies have focussed on birth weight, Mirghani and Hamud [2006] considered a broader range of birth outcomes. Specifically, they compared 168 pregnant fasters to a control group of 156 non-fasting mothers and found significantly higher rates of gestational diabetes, induced labor, cesarian sections, and admission to the special baby care unit.

\section{A.4.2 Longer-term Effects}

We are aware of just one previous study of on long-term effects of Ramadan. Azizi et al. [2004] surveyed outcomes among 191 children enrolled in 15 Islamic primary schools in Iran and their mothers about Ramadan fasting during pregnancy. Approximately half of the mothers selected for the analysis sample reported fasting. More than 1,600 mothers returned questionnaires regarding their fasting behaviour during pregnancy. However, the fraction of this initial sample who fasted during pregnancy is not reported by Azizi et al. [2004]. Among fasting mothers, those fasting during the third trimester were over-sampled. No significant difference in the IQ's of the children were found by maternal fasting behaviour. As mentioned in the main text, Ewijk [2009] analyzes long-term Ramadan effects using the Indonesian Family Life Study data. This work was inspired by ours and generally finds corroborative results.

\section{A.5 Nutrition and the Sex Ratio at Birth}

Widely studied in evolutionary biology, the Trivers-Willard hypothesis posits that the reproductive success of sons is more sensitive to maternal condition than that of daughters [Trivers and Willard, 1973]. Therefore, parents experiencing better conditions may favor 
male offspring. More generally, the sex ratio at birth and early childhood may proxy for unobserved health conditions given disproportionate male susceptibility to fetal and infant mortality [Kraemer, 2000, Mathews and Hamilton, 2005]. One proposed mechanism by which adjustment to the sex ratio may take place is through the nutritional status of the mother while pregnant [Cameron, 2004]. Roseboom et al. [2001] found that prenatal exposure to the Dutch famine of 1944-45 reduced the sex ratio of live births. Similarly, Almond et al. [2007] found the sex ratio in China was skewed toward females for cohorts born during the Great Leap Forward Famine. Askling et al. [1999] showed that women who experience severe morning sickness were much more likely to have girls.

A widely-publicized study by Mathews et al. [2008] has for the first time drawn a link between maternal nutrition prior to conception and the sex ratio at birth. The authors collected detailed information on food intake prior to pregnancy, early in pregnancy (14 weeks gestation) and late in pregnancy (28 weeks gestation) in Britain. They found no differences in the rates of male births arising from differences in nutritional intake either early or late in pregnancy but found a highly statistically significant positive relationship between high nutritional scores prior to conception and the birth of male offspring. They further examined the detailed data on sources of nutrition and found that among 133 food items consumed prior to pregnancy, only breakfast cereals was strongly associated with infant sex. The authors speculated that the mechanism underlying this connection is that the skipping of breakfast

"extends the normal period of nocturnal fasting, depresses circulating glucose levels and may be interpreted by the body as indicative of poor environmental conditions."

Mathews et al. [2008] also referenced work by Larson et al. [2001] on in vitro fertilization of bovine embryos showing that glucose "enhances the growth and development of male conceptuses while inhibiting that of females."

The study by Mathews et al. [2008] was observational and did not explore the source of dietary differences across mothers, nor did it control for some other factors known to influence the sex ratio (e.g., partnership status at the time of conception [Norberg, 2004]). Short of a controlled experiment, the research design utilized here has the advantage of leveraging plausibly exogenous differences in maternal fasting. 


\section{A.6 Hypotheses: Outcomes and Timing}

In this section, we distill findings from the biomedical literature most relevant to our Ramadan analysis. Appendix Table A1 summarizes the set of health outcomes we might expect to be affected by fasting (column 1), notes the mechanism (column 2), and lists the months of prenatal exposure that have been found or suggested to be particularly important (column 3). These hypotheses are based on either a clearly defined pathway linking fasting to a particular outcome, or an empirical result that has been established, irrespective of whether there is an explicit mechanism described in the study. In many of the studies, the period of in utero exposure was selected by design and therefore does not exclude effects in other periods.

In the case of birthweight, we describe four mechanisms through which fasting might operate and one empirical finding based on the Dutch famine. Two of the birthweight mechanisms are tightly linked to exposures occurring in early pregnancy. For several outcomes there are no clear hypotheses concerning timing that we could discern; a reasonable hypothesis would be to jointly test the effects of Ramadan exposure during all gestation months.

With respect to longer-term effects, in virtually all cases exposure to fasting during early pregnancy is the predominant hypothesis. For cognitive function, there are several arguably distinct channels through which prenatal fasting might be detrimental.

\section{B Data}

\section{B.1 Michigan Natality Microdata}

Our ancestry-based proxy for Muslim status is coded as follows. For births from 1989 to 1992, we include mothers who report their ancestry as "Arab/Middle Eastern" in the ITT (whose pregnancies also overlap with a Ramadan). Starting in 1993, several specific country codes for ancestry are reported. From 1993 to 2006 our ITT group includes mothers who report ancestry as: Arab/Middle Eastern, Arab/North African, Iran, Afghanistan, Mauritania, Somalia, Turkey or Western Sahara. Overall, 96\% of our treatment group report their ancestry as Arab/Middle Eastern, hence we refer to the group as Arabs.

We also implement several other sample selection rules to minimize measurement error and misclassification of Muslims into the control group. We dropped births with no reported ancestry or where the ancestry might possibly include parents who are practicing 
Muslims (e.g. Southeastern Asians). We also dropped non-Arab Blacks to avoid the possibility that there might be "Black Muslims" in our sample. We also dropped twin births and restricted the sample to births among mothers between the ages of 14 and 45 .

The summary statistics are shown in Appendix Table A2. Arab mothers reported a year less education than non-Arab mothers on average, and are substantially more likely to receive Medicaid (46\% versus 27\%). Arab families are also larger (average parity is $18 \%$ higher for Arabs). Despite these differences in socioeconomic measures, birth outcomes are more similar. Rates of low birth weight and prematurity are actually slightly lower for Arabs than for non-Arabs. The geographic distribution of Arabs by zipcode in Michigan is shown in Appendix Figure A2. Somewhat surprisingly perhaps, Arabs do not appear noticeably more concentrated around the Dearborn and Detroit area than non-Arabs (Panel A).

The key variables for assigning in utero Ramadan exposure are birth date and gestation length. Michigan natality data include exact date of birth and a self-reported date of last menstrual period (LMP) for about 70 percent of the sample. The problem of selective reporting of LMP based on socioeconomic status is well known [Hediger et al., 1999]. There is also a field containing the physician's estimate of gestation length, but we do not know how it is calculated or when during gestation. ${ }^{6}$ We follow related epidemiological studies that utilize a simple algorithm for coding gestation (e.g., Siega-Riz et al. [2001], Herrmann et al. [2001]): gestation based on LMP is used except if it is missing or if it differs with physician estimated gestation by more than 14 days, in which case the physician estimated measure is substituted.

Appendix Figure A3 provides a hypothetical example to illustrate how our daily measures of Ramadan exposure are calculated. In 1989, Ramadan began on April 7th and ended on May 6th. For someone who was conceived on April 6th, his or her entire first month of gestation would overlap with Ramadan, i.e. exppct=1. Since during this Ramadan, daylight hours averaged about 13.7 hours per day, compared to 15.2 during the summer solstice, the hours exposure measure (exphrspct) peaks at about 0.9.

\footnotetext{
${ }^{6} \mathrm{~A}$ key concern is that this could be endogenous to Ramadan exposure. For example, if Ramadan affects fetal size and if physician estimates of LMP are based on measures of fetal size, this could lead to mis-measurement of the timing of Ramadan exposure. In addition, this measure might not be calculated uniformly and may depend on the timing of the first doctor visit and could therefore, be correlated with mother's socioeconomic status.
} 


\section{B.2 Uganda Census 2002}

The Uganda Census contains roughly 2.5 million records (10\% sample). Our main analysis sample includes men and women ages 20 to 80 . Individuals whose birth month or birth year were imputed are dropped. ${ }^{7}$ For each outcome measure, we recoded those with imputed data to missing. The disability question in the Uganda survey instrument asks: "Does (name) have any difficulty in moving, seeing, hearing, speaking difficulty, mental or learning difficulty, which has lasted or is expected to last 6 months or more?" The following specific disabilities are recorded in the dataset: blind or vision impaired, deaf or hearing impaired, mute, disability affecting lower extremities, disability affecting upper extremities, mental/learning disabilities and psychological disabilities. The original unharmonized variables label the last two variables "mental retardation" and "mental illness" while IPUMS-I relabelled them as "mental" and "psychological". Our own reading of the instructions to the Uganda Census enumerators suggests that this relabelling was indeed appropriate. The former measure appears to identify those with "mental or learning disabilities" while the latter identifies those exhibiting "strange behaviors". A subsequent question asks about the origin of the reported disability. The responses are coded into the following categories: congenital, disease, accident, aging, war injury, other or multiple causes.

The summary statistics are reported in Appendix Table A3. In contrast to Michigan, Uganda Muslims tend to have higher average SES. Muslims are less likley to be illiterate than non-Muslims (30\% versus 36\%) and completed more schooling. Disability rates for Muslims are also lower $-3.8 \%$ versus $5.2 \%$ for non-Muslims. Both Muslims and nonMuslims share a strong seasonality in the frequency of births by month. For both groups, birth in June was more than 50\% more likely than birth in December. The frequency distribution across Ramadan ITT gestation months is much more uniform, and similar between Muslims and non-Muslims.

ITT assignment is determined by the reported birth month. We found age heaping: spikes in the number of respondents reporting of ages ending in zeroes (e.g. 20, 30, 40), suggesting measurement error. We therefore excluded records reporting these roundnumber ages.

\footnotetext{
${ }^{7}$ The IPUMS-I "unharmonized" variables contain imputation flags. We allowed records with "logical imputations" but dropped records imputed by "hot-deck".
} 


\section{B.3 Iraq Census 1997}

The Iraq Census is also a 10 percent sample. We dropped individuals who reported ages ending in seven because of heaping at those ages. We also drop those reporting birth months of January and July because of heaping at those months. We also drop those born before 1958 due to extremely high levels of missing values for month of birth. This leaves us with a sample of over 250,000 individuals between the ages of 20 and 39 in 1997.

The reduced number of birth cohorts can potentially affect our ability to separate the effects of Ramadan exposure from season of birth trends for outcomes that are highly seasonal. We found school related outcomes to be highly seasonal in Iraq. We suspect that this is due to institutional factors that determine school starting or leaving ages at particular dates of the calendar year. We find, for example, that mean schooling levels were about 12 percent higher for those born between September and December than for those born between February and April. Because of the timing of Ramadan among the 1958 to 1977 cohorts, those born between February through April had no exposure to Ramadan in the first month of pregnancy, while those born between September and December had mean exposure of about 0.11 thereby inducing a highly positve correlation between early Ramadan exposure and schooling. In contrast, we find no evidence of strong season of birth patterns in our main outcomes of interest. For example, mean disability rates are only about 1.2 percent lower for those born in September through December compared to those born between February and April with no discernible monthly pattern.

\section{B.4 US Census 1980, ACS, 2005-2007}

We assigned our Muslim proxy to respondents born in a country which currently has at least 80 percent Muslims. ${ }^{8}$ We used the following 38 countries: Saudi Arabia, Somalia, Afghanistan, Maldives, Western Sahara, Turkey, Iran, Algeria, Mauritania, Yemen, Tunisia, Oman, Comoros, Djibouti, Morocco, Pakistan, Libya, Iraq, Iraq/Saudi Arabia, Tajikistan, Jordan, Qatar, Senegal, Azerbaijan, Egypt, Mali, Niger, Gambia, Uzbekistan, Turkmenistan, Indonesia, Bangladesh, Syria, Guinea, Kuwait, Bahrain, West Bank and Gaza. We excluded individuals who reported languages that would suggest they were non-Muslims. ${ }^{9}$ We also dropped Iranian immigrants living in California who are predominantly Jewish.

\footnotetext{
${ }^{8}$ We took estimates derived from US State Departments's International Religious Freedom Report, the CIA World Factbook and Adherents.com as reported on the following Wikipedia URL: http://en.wikipedia.org/wiki/Islam_by_country

${ }^{9}$ For example, some individuals born in Indonesia may report "Dutch" as their language.
} 
In order to roughly gauge the extent of classification error, we can consider data from the 2001 Canada Census, which includes measures both of religion and country of birth. $67 \%$ of Canadian immigrants born in our predominantly-Muslim countries reported Muslim as their religion. ${ }^{10}$ If the immigration patterns were assumed to be identical, then this would imply that roughly one in three of our sample of Census sample will not observe the Ramadan fast because they are not Muslim. Our control sample was restricted to whites born in the United States who did not report ancestries outside of the US or Western Europe. We chose not to use reported ancestry for assigning the Muslim proxy because of high rates of underreporting and the fact that it would combine first and second generation immigrants. We might suspect that that Ramadan observance is higher for first generation immigrants.

For earnings we use the CPI to convert values into 1997 dollars and restrict the sample to those aged 20 to 60 years.

\section{B.5 Other Suitable Datasets?}

The Uganda and Iraq Census microdata were obtained from the Integrated Public Use Microdata Series - International (IPUMS-I). Other potentially relevant IPUMS-I samples are those for Egypt, Jordan, and Malaysia. Each has a large population of Muslims with Census data that purportedly include birth month. ${ }^{11}$ Religion is not reported for Egypt and Jordan, but like Iraq, are overwhelmingly Muslim. However, in Egypt $85 \%$ of the sample is missing birth month. $40 \%$ are missing birth month in Malaysia, and only .5\% of adults report a work disability. In Jordan's data, birth year and place of birth are missing.

In the US, month of birth is not reported in the decennial Census. While the National Health Interview Survey (NHIS) reports birth month, it does not disclose religion, detailed ethnicity, or country of birth.

\section{Birth Outcomes by Gestation Length}

As noted in the main text, variation in gestation length can generate compositional effects for pregnancies exposed to Ramadan late in gestation. For example, pregnancies with exposure to Ramadan in month 9 of pregnancy are exclusively full-term, but ITT estimates

\footnotetext{
${ }^{10}$ We thank Kevin Milligan (UBC) for providing these estimates.

${ }^{11}$ Birth month and religion are available in the census of South Africa (unharmonized variables in IPUMS-I), but South Africa's Muslim population is relatively small (roughly 1.5\% of the population).
} 
of the month 9 effect include premature births where Ramadan fell after delivery. Even for earlier months of pregnancy, the relationship to the ITT may differ depending on gestation length. Finally, gestation itself may respond to the ITT.

In Appendix Table A4, we vary the samples used to estimate birthweight effects based on the length of gestation. In column (1) we start with a sample of all births with gestation length 25 weeks to 42 weeks allowing us to include preterm births. The coefficients for months 1 to 5 are interpretable for all sample members. ${ }^{12}$ We then progressively tighten the sample restriction by increasing the lower bound on gestation age producing samples of length 31-42 weeks in column (2), 35-42 weeks in column (3) and 39-42 weeks in column (4). This gradually increases the number of exposure month coefficients that can be interpreted. Interestingly, this does not appear to have any pronounced effects on the results. With the larger samples that include some preterm births, exposure during the sixth months is significant at the 10 percent level in two of the three specifications. The gestation samples that include pre-term births now provide additional evidence (on top of the "no gestation" sample results from Table 1 of the main text), that the coefficients are jointly different from zero with significance levels ranging from 6.1 percent to 12.4 percent.

In column (5) we attempt to address the fact that out ITT estimates may be attenuated by the inclusion of Chaldeans, who are not Muslim but might self identify as Arab. Specifically we use the sample of full-term births and drop mothers whose zipcode of residence has a ratio of Chaldeans to Arabs of greater than 0.5 according to the 2000 Census. This drops our sample by more than 25 percent and raises the standard errors considerably. However, there is some suggestive evidence of a stronger ITT effect. The most dramatic change is for exposure in the 7th month of gestation where we now see an effect: nearly a 60 gram drop in birthweight that is significant at the 1 percent level. The $p$-value on the $F$-test of joint significance also falls to 0.071 from 0.277 in column (4). In other specifications we have not always found much of a difference between the overall sample and the sample that drops heavily Chaldean zipcodes. This may be due to the large geographic overlap in the concentrations of Arabs and Chaldeans zipcodes and the relatively coarse approach dictated by the available data. In this sub-sample, we are arguably, estimating the effects of Ramadan exposure among Arabs in less concentrated areas where observance rates may be lower.

In columns (6) through (9) we estimate the effects of in utero Ramadan exposure on

\footnotetext{
${ }^{12}$ For example, exposure in months 6 to 9 will include the effects of Ramadan exposure in the postnatal period for the small subsample of those with only 25 weeks gestation.
} 
gestation weeks using the same approach on the full sample of Arabs. Among those with 25-42 weeks gestation, we estimate that Ramadan exposure during the second and fifth months of pregnancy reduces gestational age by a little more than 0.1 weeks or by roughly a day $(p<0.10)$. However, these are the only months where exposure is statistically significant and we cannot reject that the first five gestation months jointly, have no effect. The effect from month 5 exposure weakens a bit as the sample is gradually restricted. Interestingly, column (9) shows that when the sample is confined to only full term births, four gestation months $(2,3,5$ and 8$)$ are significant at at least the 10 percent level. Finally, in column (10) with the more restricted sample of non-Chaldean zipcodes we find a highly significant effect from second month exposure. In order to assess what portion of the birthweight effect might be attributed to decreased gestation, we ran a separate regression of birthweight on gestation for the sample of non-Arab mothers and found that each additional week of gestation adds about 165 grams. This suggests that a reduction in gestation of 0.1 weeks is associated with a 16 gram reduction in birthweight. From this rough exercise, it appears that less than half of the overall reduction in birthweight of around 40 grams that we typically estimate in Tables 1 and Appendix Table A4 is due to reduced gestation as opposed intrauterine growth restriction (IUGR). For those exposed in the first month of pregnancy, it appears that virtually all of the birthweight reduction is due to IUGR.

\section{Distributional Effects on Birth Weight}

In Figure A4 we show which parts of the birthweight distribution are affected by early exposure to Ramadan fasting. We plot kernal densities comparing the birthweight distribution of those Arabs with no in utero exposure to those who had a significant exposure to Ramadan in the first month of gestation (exphrspct1 $>0.5) .{ }^{13}$ Most of the effect is in the middle part of the distribution. Specifically, those with first month exposure to Ramadan are more likely to have birthweight between 2800 and 3200 grams and less likely to have birthweight between 3250 and 3900 grams. ${ }^{14}$ This suggests that little of the effect is at the low end of the distribution among those classified as "low birthweight" $(<2500$ grams).

\footnotetext{
${ }^{13}$ We also ran linear probability regressions using indicator variables of being in specific intervals of the birthweight distribution (e.g. 300-600 grams, 600-900 grams etc.) as an outcome including our other controls and obtained very similar results.

${ }^{14}$ There are also small differences between the samples in the interval from 2100 grams to 2700 grams, and for birthweight greater than 4500 grams.
} 


\section{References}

A Adlouni, N Ghalim, R Sale, N Had, and A Bensliman H Parra and. Beneficial effect on serum apo ai, apo b and lp ai levels of ramadan fasting. Clinica Chimica Acta, 271 (2):179-189, March 1998.

Douglas Almond, Lena Edlund, Hongbin Li, and Junsen Zhang. Long-term effects of the 1959-61 china famine: Mainland china and hong kong. NBER Working Paper No. 13384, September 2007.

Joshua D. Angrist and Jörn-Steffen Pischke. Mostly Harmless Econometrics: An Empiricist's Companion. Princeton University Press, Princeton, New Jersey, 2009.

M Arab. Ketonuria and serum glucose of fasting pregnant women at the end of a day in ramadan. The Journal of Physiology, 553(2):637-647, 2003.

Malihe Arab and Shahla Nasrollahi. Interrelation of ramadan fasting and birth weight. Medical Journal of the Islamic Academy of Sciences, 14(3):91-95, 2001.

J. Askling, G. Erlandsson, M. Kaijser M, O. Akre, and A. Ekbom. Sickness in pregnancy and the sex of the child. Lancet, 354(9195):2053, December 1999.

Fereidoun Azizi, Hossein Sadeghipour, Behnam Siahkolah, and Nasrollah Rezaei-Ghaleh. Intellectual development of children born to mothers who fasted during pregnancy. International Journal of Vitamin and Nutrition Research, 74(5):374-380, September 2004.

Elissa Z. Cameron. Facultative adjustment of mammalian sex ratios in support fo the trivers-willard hypothesis: evidence for a mechanism. Proceedings of the Royal Society B: Biological Sciences, 271(1549):1723-1728, 2004.

TJ Cole. Seasonality and Human Ecology, chapter Seasonal Effects on Physical Growth and Human Development, pages 89-106. Cambridge University Press, Cambridge, 1993.

JH Cross, J Eminson, and BA Wharton. Ramadan and birth weight at full term in asian moslem pregnant women in birmingham. Archives of Disease in Childhood, 653: 1053-56, 1990.

E. Dikensoy, O. Balat, B. Cebesoy, A. Ozkur, H. Cicek, and G. Can. The effect of Ramadan fasting on maternal serum lipids, cortisol levels and fetal development. Archives of gynecology and obstetrics, 279(2):119, 2009.

Janet A. DiPietro, Kathleen Costigan, Marc H. Bornstein, Chun-Shin Hahn, and Aristide Achy-Brou. Fetal heart rate and variability: Stability and prediction to developmental outcomes in early childhood. Child Development, 78(6):1788-1798, November/December 2007.

PM Eaton and PA Wharton. Applied Nutrition, chapter Sorrento Study of Nutrition in Pregnancy, pages 89-91. John Libbey, London, 1982. 
Reyn Van Ewijk. Long-term health effects on the next generation of ramadan fasting during pregnancy. April 2009. CEP Discussion Paper No 926.

Mary L. Hediger, Mary D. Overpeck, Andrea McGlynn, Robert J. Kuczmarski, Kurt R. Maurer, and William W. Davis. Growth and fatness at three to six years of age of children born small- or large-for-gestational age. Pediatrics, 104(3):e33, 1999.

Tracy S Herrmann, Anna Maria Siega-Riz, Calvin J Hobel, Chandra Aurora, and Christine Dunkel-Schetter. Prolonged periods without food intake during pregnancy increase risk for elevated maternal corticotropin-releasing hormone concentrations. American Journal of Obstetrics and Gynecology, 185(2):403-412, 2001.

Ann Hoskins. Pregnancy and fasting during ramadan. British Medical Journal, 304(6836): 1247, May 1992.

ES Hunter and TW Sadler. D-(-)-beta hydroxybutyrate-induced effects on mouse embryos in vitro. Teratology, 36:259-64, 1987.

R Husain, MT Duncan, SH Cheah, and SL Chng. Effects of fasting in ramadan on tropical asiatic moslems. British Journal of Nutrition, 5833(1):41-48, 1987.

Vincent W.V. Jaddoe and Jacqueline C.M. Witteman. Hypotheses on the fetal origins of adult diseases: Contributions of epidemiological studies. European Journal of Epidemiology, 21:91-102, 2006.

J Joosoph and S.L. Yu. A survey of fasting during pregnancy. Singapore Medical Journal, 45(12):583-586, 2004.

Amita Kapoor, Elizabeth Dunn, Alice Kostaki, Marcus H. Andrews, and Stephen G. Matthews. Fetal programming of hypothalamo-pituitary-adrenal function: Prenatal stress and glucocorticoids. Journal of Physiology, 572(1):31-44, 2006.

Zohreh Kavehmanesh and Hassan Abolghasemi. Maternal ramadan fasting and neonatal health. Journal of Perinatology, 24:748-750, 2004.

Sebastian Kraemer. The fragile male. BMJ, 321(7276):1609-1612, 2000.

SJ Langan, IJ Deary IJ, DA Hepburn, and BM Frier. Cumulative cognitive impairment following recurrent severe hypoglycaemia in adult patients with insulin-treated diabetes mellitus. Diabetologia, 34:337-344, 1991.

Melissa A. Larson, Koji Kimura, Michael Kubisch, and R. Michael Roberts. Sexual dimorphism among bovine embryos in their ability to make the transition to expanded blastocyst and in the expression of the signaling molecule ifn-t. PNAS, 98(17):96779682, 2001.

Abdulwahab M. Makki. Impact of ramadan fasting on birth weight in 4 hospitals in sanaa city,yemen. Saudi Medical Journal, 23(11):1419-1420, 2002. 
Ashok Malhotra, P.H. Scott, J.S. Scott, H. Gee, and B.A. Wharton. Metabolic changes in asian muslim pregnant mothers observing the ramadan fast in britian. British Journal of Nutrition, 61(3):663-672, May 1989.

Kamal Mohmoud Saleh Mansi. Study the effects of ramadan fasting on the serum glucose and lipid profile among healthy jordanian students. American Journal of Applied Sciences, 3(8):565-569, 2007.

Fiona Mathews, Paul J. Johnson, and Andrew Neil. You are what your mother eats: evidence for maternal preconception diet influencing foetal sex in humans. Proceedings of the Royal Society B, pages 1-8, April 2008.

T.J. Mathews and Brady E. Hamilton. Trend analysis of the sex ratio at birth in the united states. National Vital Statistics Reports, 53(20), June 142005.

Hisham M. Mirghani, Muntha Salem, and Sarath D. Weerasinghe. Effect of maternal fasting on uterine arterial blood flow. Journal of Obstetrics and Gynaecology Research, 33(2):151-154, April 2007.

Hisham M. Mirghani, Sarath Weerasinghe, Shamsaa Al-Awar, Lolowa Abdulla, and Mutairu Ezimokhai. The effect of intermittent maternal fasting on computerized fetal heart tracing. Journal of Perinatology, 25:90-92, 2005.

H.M. Mirghani and Omer A. Hamud. The effect of maternal diet restriction on pregnancy outcome. American Journal of Perinatology, 23(1):21-24, 2006.

H.M. Mirghani, S.D. Weerasinghe, J.R. Smith, and M. Ezimokhai. The effect of intermittent maternal fasting on human fetal breathing movements. Journal of Obstetrics and Gynaecology, 24(6):635-637, September 2004.

DCP Moore, M Stanisstreet, and CA Clarke. Morphological and physiological effects of beta-hydroxybutyrate on rat embryos grown in vitro at different stages. Teratology, 40: 237-51, 1989.

Hidenori Nishina, Lucy R. Green, Hugh H. G. McGarrigle, David E. Noakes, Lucilla Poston, and Mark A. Hanson. Effect of nutritional restriction in early pregnancy on isolated femoral artery function in mid-gestation fetal sheep. Acta Medica Iranica, 42 (3):209-212, 2004.

Karen Norberg. Partnership status and the human sex ratio at birth. Proceedings of the Royal Society B: Biological Sciences, 271(1555):2403-2410, 2004.

A.A. Opaneye, D.D. Villegas, and Ali Abdel Azeim. Islamic festivals and low birthweight infants. The Journal of the Royal Society for the Promotion of Health, 110(3):106-107, June 1990.

Rebecca C. Painter, Tessa J. Roseboom, and Otto P. Bleker. You are what your mother eats: evidence for maternal preconception diet influencing foetal sex in humans. Reproductive Toxicology, 20:345-352, 2005. 
AM Prentice, A Prentice, WH Lamb, PG Lunn, and S. Austin. Metabolic consequences of fasting during ramadan in pregnant and lactating women. Human nutrition. Clinical nutrition, 37(4):283-94, July 1983.

J Ramadan, G Telahoun, NS Al-Zaid, and M Barac-Nieto. Responses to exercise, fluid, and energy balances during ramadan in sedentary and active males. Nutrition, 15(10): 735-739, 1999.

T Rizzo, BE Metzger, WJ Burns, and K Burns. Correlations between antepartum maternal metabolism and child intelligence. New England Journal of Medicine, 325:911-916, 1991.

Trinka Robinson and Jeanne Raisler. Each one is a doctor for herself: Ramadam fasting among pregnant muslim women in the united states. Ethnicity and Disease, 15:S1-99 to S1-103, Winter 2005.

Tessa J. Roseboom, Jan H.P. Meulen, Anita C.J. Ravelli, Clive Osmond, David J.P. Barker, and Otto P. Bleker. Effects of prenatal exposure to the dutch famine on adult disease in later life: An overview. Twins Research, 4(5):293-298, October 2001.

Theresa O Scholl, MaryFran Sowers, Xinhua Chen, and Carine Lenders. Maternal glucose concentration influences fetal growth, gestation and pregnancy complications. American Journal of Epidemiology, 154(6):514-520, 2001.

Shole Shahgheibi, Ebrahim Ghadery, Arash Pauladi, Sabah Hasani, and Syroos Shahsawari. Effects of fasting during the third trimester of pregnancy on neonatal growth indices. Annals of Alquds Medicine, 1426(2):58-62, 2005.

EA Sheehan, F Beck, CA Clarke, and M Stanisstreet. Effects of beta-hydroxybutyrate on rat embryos grown in culture. Experentia, 41:273-75, 1985.

Anna Maria Siega-Riz, Tracy Hermann, David A Savitz, and John M Thorp. Frequency of eating during pregnancy and its effect on preterm delivery. American Journal of Epidemiology, 153(7):647-652, 2001.

Hamed R Takruri. Effect of fasting in ramadan on body weight. Saudi Medical Journal, 10(6):491-494, 1989.

Edith W. M. T. ter Braak, Inge M. Evers, D. Willem Erkelens, and Gerard H. A. Visser. Maternal hypoglycemia during pregnancy in type 1 diabetes: maternal and fetal consequences. Diabetes/Metabolism Research And Reviews, 19:96-105, 2002.

Robert L. Trivers and Dan E. Willard. Natural selection and the ability to vary the sex ratio of offspring. Science, 179(4068):90-92, January 1973. 


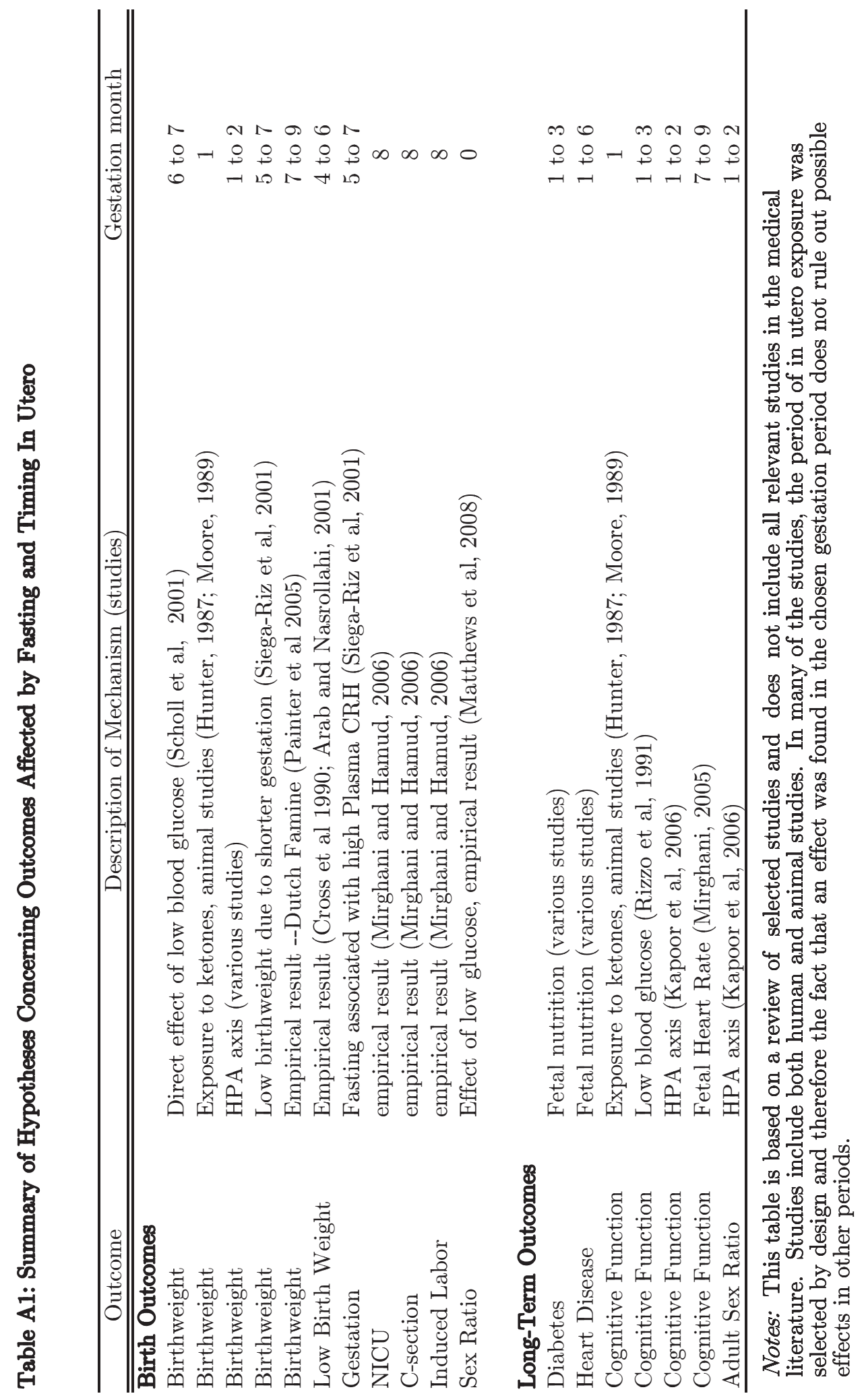


Table A2: Summary Statistics for Michigan Natality Data, 1989-2006

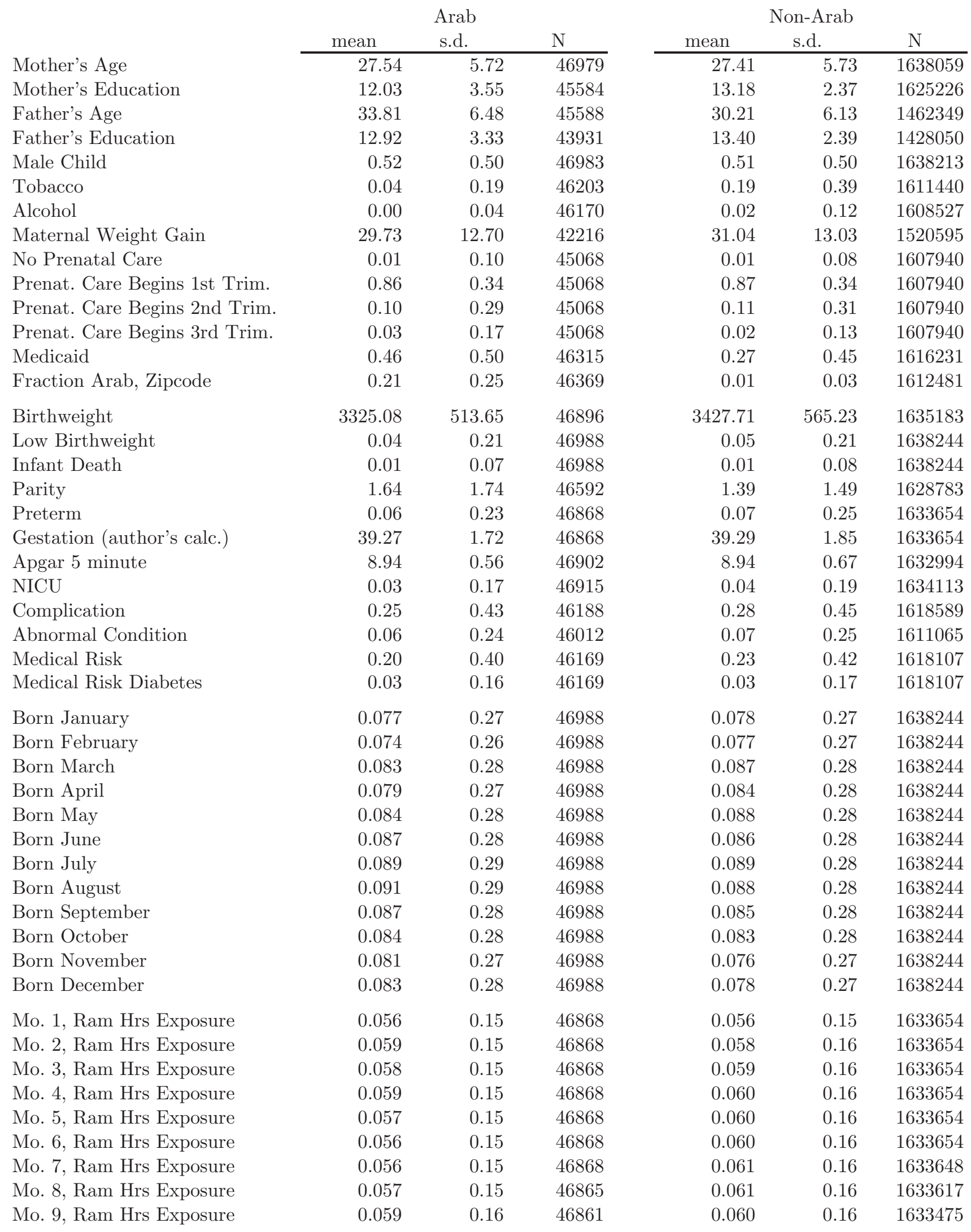


Table A3: Summary Statistics for Uganda Census Sample

female

age

illiterate

years of schooling

no schooling

employed

elementary occupation

home ownership (males)

\# of wives (males)

disability

blind/vision impaired

deaf/hearing impaired

mute/speech impaired

lower extremities

upper extremities

mental/learning

psychological

epilepsy

rheumatism

congen

disease

accident

occupational injury

war injury

aging

Born January

Born February

Born March

Born April

Born May

Born June

Born July

Born August

Born September

Born October

Born November

Born December

rampct1

rampct2

rampct3

rampct4

rampct5

rampct6

rampct7

rampct8

rampct9
Muslim

\begin{tabular}{rrr} 
mean & \multicolumn{1}{c}{ s.d. } & \multicolumn{1}{l}{$\mathrm{N}$} \\
\hline 0.494 & 0.500 & 81197 \\
34.546 & 12.675 & 81197 \\
0.304 & 0.460 & 78990 \\
6.944 & 3.269 & 60117 \\
0.247 & 0.431 & 80142 \\
0.660 & 0.474 & 74348 \\
0.042 & 0.200 & 46284
\end{tabular}

$\begin{array}{ll}0.0380 & 0.191-8092\end{array}$

$\begin{array}{lll}0.0106 & 0.102 & 80922\end{array}$

$\begin{array}{lll}0.0038 & 0.062 & 80923\end{array}$

$\begin{array}{lll}0.0009 & 0.030 & 80921\end{array}$

$\begin{array}{lll}0.0125 & 0.111 & 80921\end{array}$

$\begin{array}{lll}0.0039 & 0.062 & 80921\end{array}$

$\begin{array}{lll}0.0014 & 0.037 & 80921\end{array}$

$0.0014 \quad 0.038$

$0.0005 \quad 0.023$

$0.0009 \quad 0.030$

$0.0050 \quad 0.070$

0.0203

0.141

0.0056

0.0053

0.0007

0.0053

0.105

0.076

0.072

0.110

0.070

0.102

0.094

0.079

0.079

0.078

0.069

0.067

0.081

0.079

0.077

0.084

0.086

0.084

0.087

0.090

0.087
0.074

0.072

0.027

0.072

0.306

0.265

0.258

0.313

0.256

0.302

0.292

0.269

0.269

0.268

0.253

0.250

0.215

0.214

0.211

0.219

0.223

0.217

0.222

0.226

0.221
80921

80921

80921

80921

80924

80921

80921

80921

80921

81197

81197

81197

81197

81197

81197

81197

81197

81197

81197

81197

81197

81197

81197

81197

81197

81197

81197

81197

81197

81197
Non-Muslim

\begin{tabular}{rrr} 
mean & \multicolumn{1}{c}{ s.d. } & \multicolumn{1}{c}{$\mathrm{N}$} \\
\hline 0.498 & 0.500 & 643300 \\
36.697 & 13.907 & 643300 \\
0.356 & 0.479 & 626473 \\
6.797 & 3.599 & 449968 \\
0.290 & 0.454 & 635282 \\
0.631 & 0.483 & 581842 \\
0.042 & 0.200 & 347248
\end{tabular}

$\begin{array}{lll}0.0521 & 0.222 & 640825 \\ 0.0149 & 0.121 & 640789 \\ 0.0061 & 0.078 & 640781 \\ 0.0015 & 0.038 & 640780 \\ 0.0161 & 0.126 & 640794 \\ 0.0056 & 0.075 & 640779 \\ 0.0017 & 0.041 & 640777 \\ 0.0020 & 0.045 & 640776 \\ 0.0009 & 0.031 & 640777 \\ 0.0016 & 0.039 & 640776\end{array}$

$\begin{array}{lll}0.0058 & 0.076 & 640778\end{array}$

$\begin{array}{lll}0.0283 & 0.166 & 640803\end{array}$

$\begin{array}{lll}0.0079 & 0.088 & 640782\end{array}$

$\begin{array}{lll}0.0074 & 0.086 & 640786\end{array}$

$\begin{array}{lll}0.0013 & 0.036 & 640777\end{array}$

$\begin{array}{lll}0.0074 & 0.086 & 640786\end{array}$

$\begin{array}{lll}0.096 & 0.294 & 643300\end{array}$

$\begin{array}{lll}0.075 & 0.263 \quad 643300\end{array}$

$0.072 \quad 0.259 \quad 643300$

$\begin{array}{lll}0.106 & 0.308 & 643300\end{array}$

$0.070 \quad 0.256 \quad 643300$

$\begin{array}{lll}0.105 & 0.307 & 643300\end{array}$

$\begin{array}{lll}0.098 & 0.298 & 643300\end{array}$

$\begin{array}{lll}0.083 & 0.275 & 643300\end{array}$

$\begin{array}{lll}0.081 & 0.272 & 643300\end{array}$

$\begin{array}{lll}0.077 & 0.267 & 643300\end{array}$

$\begin{array}{lll}0.069 & 0.253 & 643300\end{array}$

$\begin{array}{lll}0.068 & 0.251 & 643300\end{array}$

$\begin{array}{lll}0.081 & 0.216 & 643300\end{array}$

$\begin{array}{lll}0.079 & 0.215 & 643300\end{array}$

$\begin{array}{lll}0.078 & 0.212 & 643300\end{array}$

$\begin{array}{lll}0.083 & 0.218 & 643300\end{array}$

$\begin{array}{lll}0.085 & 0.221 & 643300\end{array}$

$\begin{array}{lll}0.083 & 0.217 & 643300\end{array}$

$\begin{array}{lll}0.085 & 0.221 & 643300\end{array}$

$\begin{array}{lll}0.089 & 0.226 & 643300\end{array}$

$\begin{array}{lll}0.087 & 0.221 & 643300\end{array}$ 


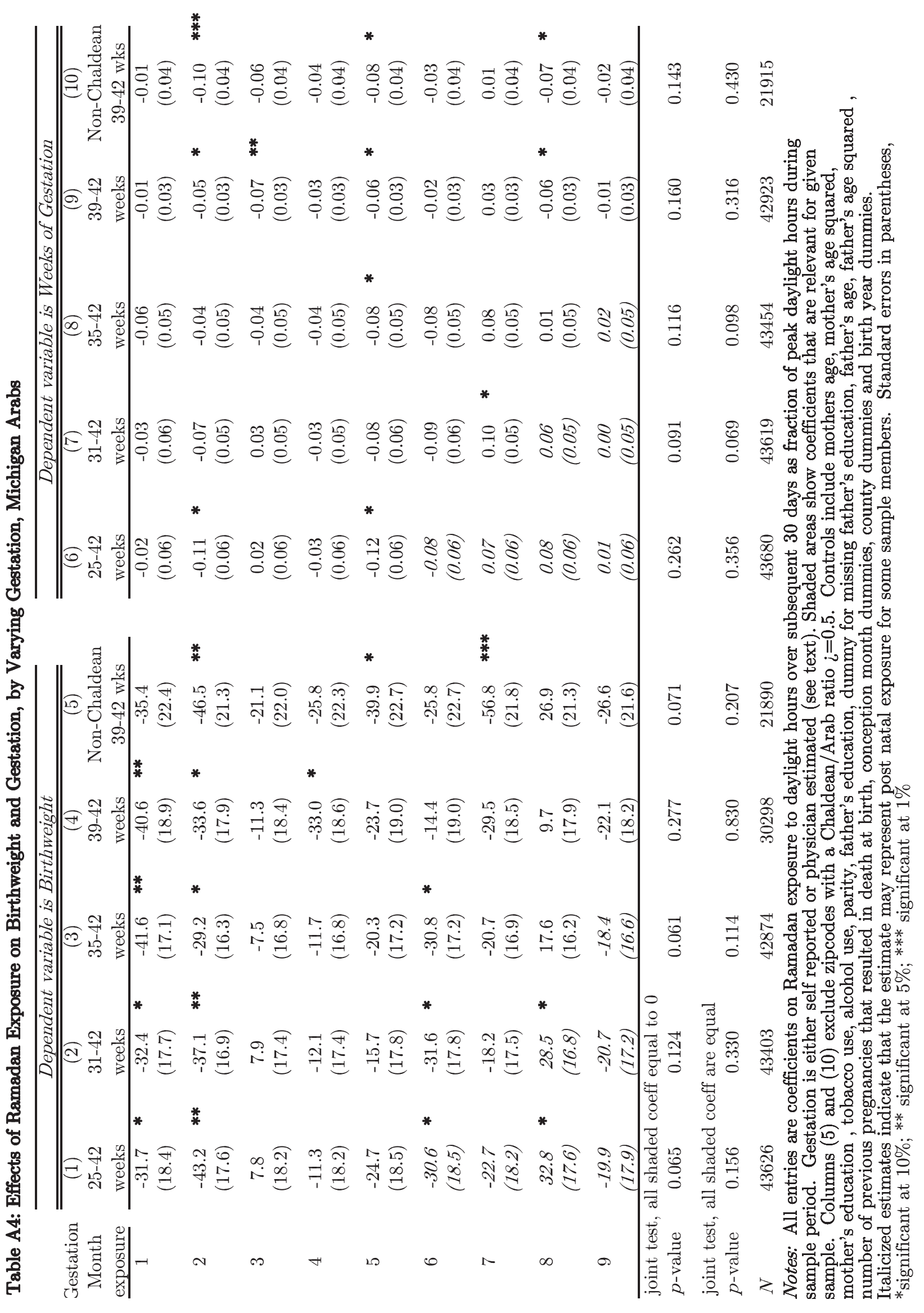




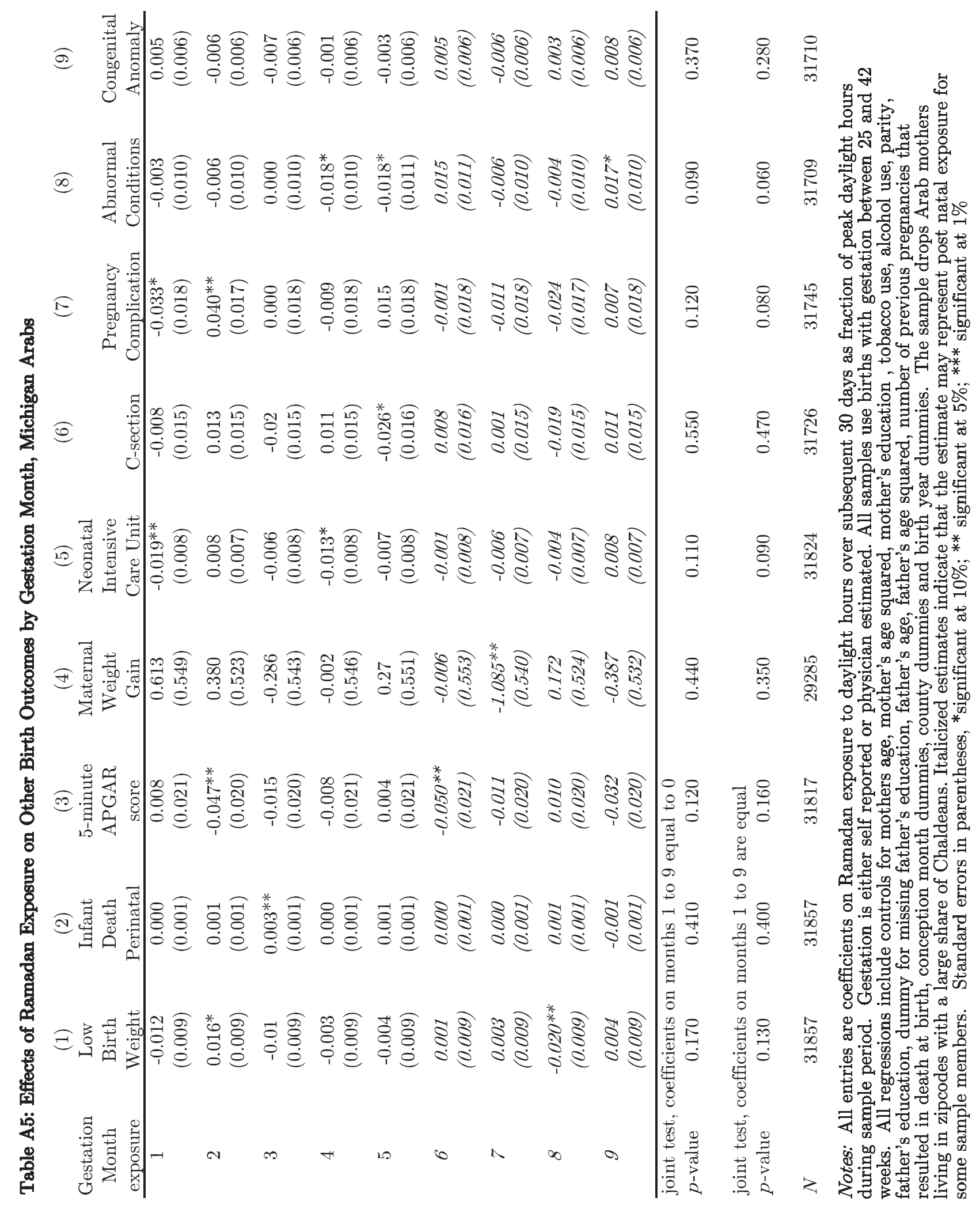




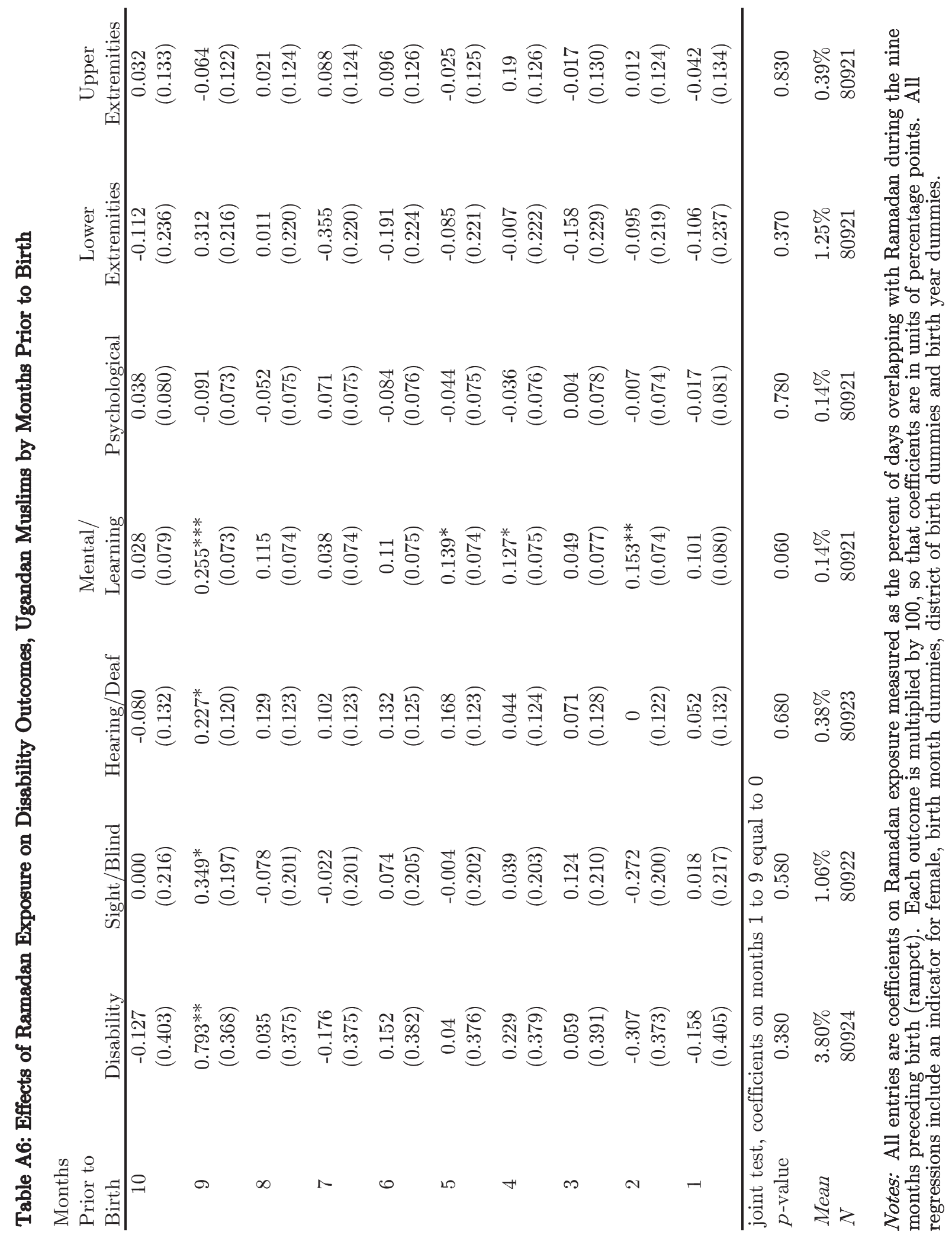




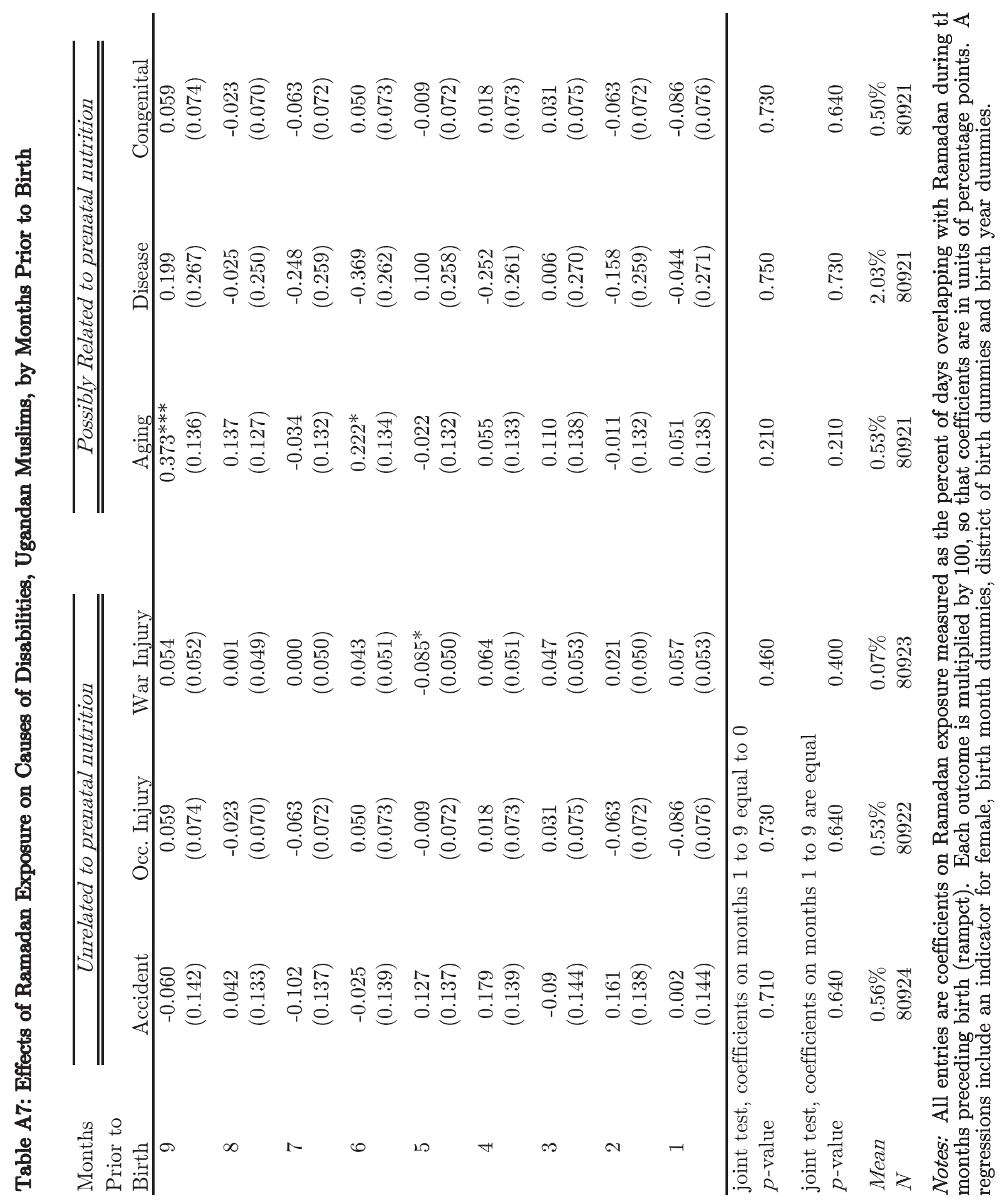


Figure A1: Women's Weight Change Around Ramadan in Gambia

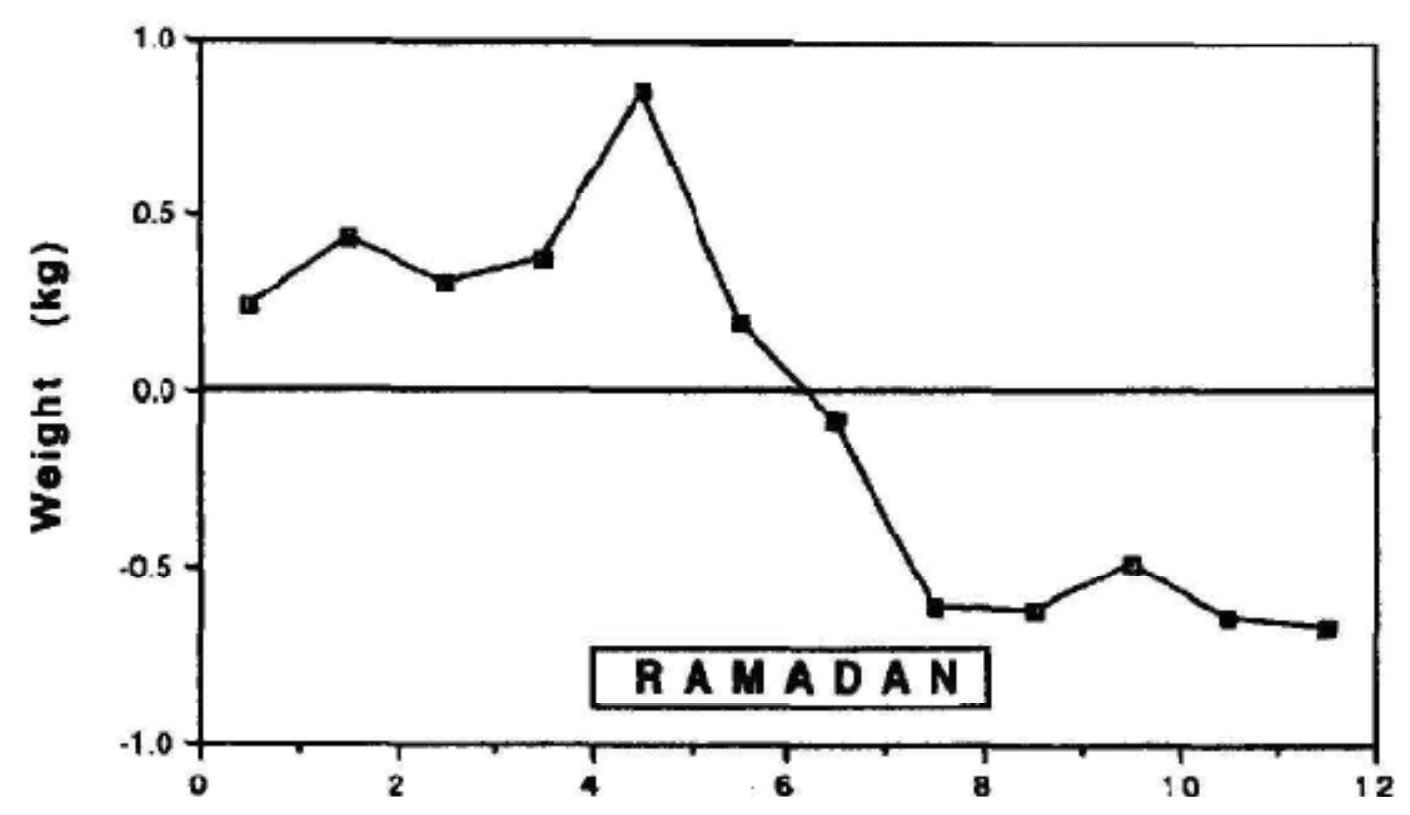

Fig. 8.5. Weight change in Gambian women during 3 months around the fast of Ramadan, expressed relative to mean weight for the other 9 months of the year. Each point has a standard error of about $0.15 \mathrm{~kg}$. The data are adjusted for calendar month and year of measurement, and stage of pregnancy/lactation, using within-subject regression.

Source: Cole (1993) 
Figure A2: Michigan Arab Population by Zipcode

Panel A: Quartiles of the Arab Population

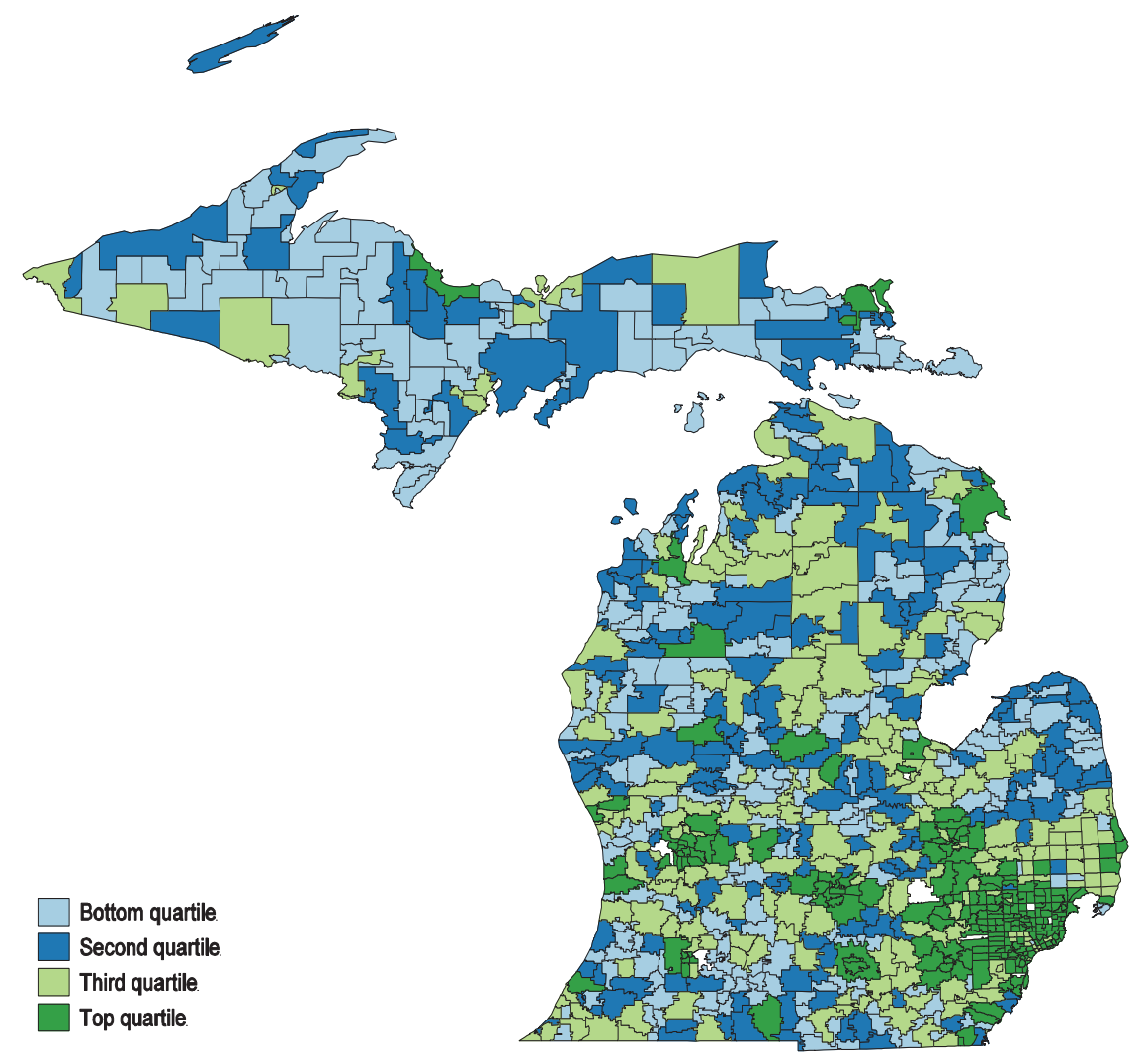

Panel B: Ratio of the Chaldean to Arab Population

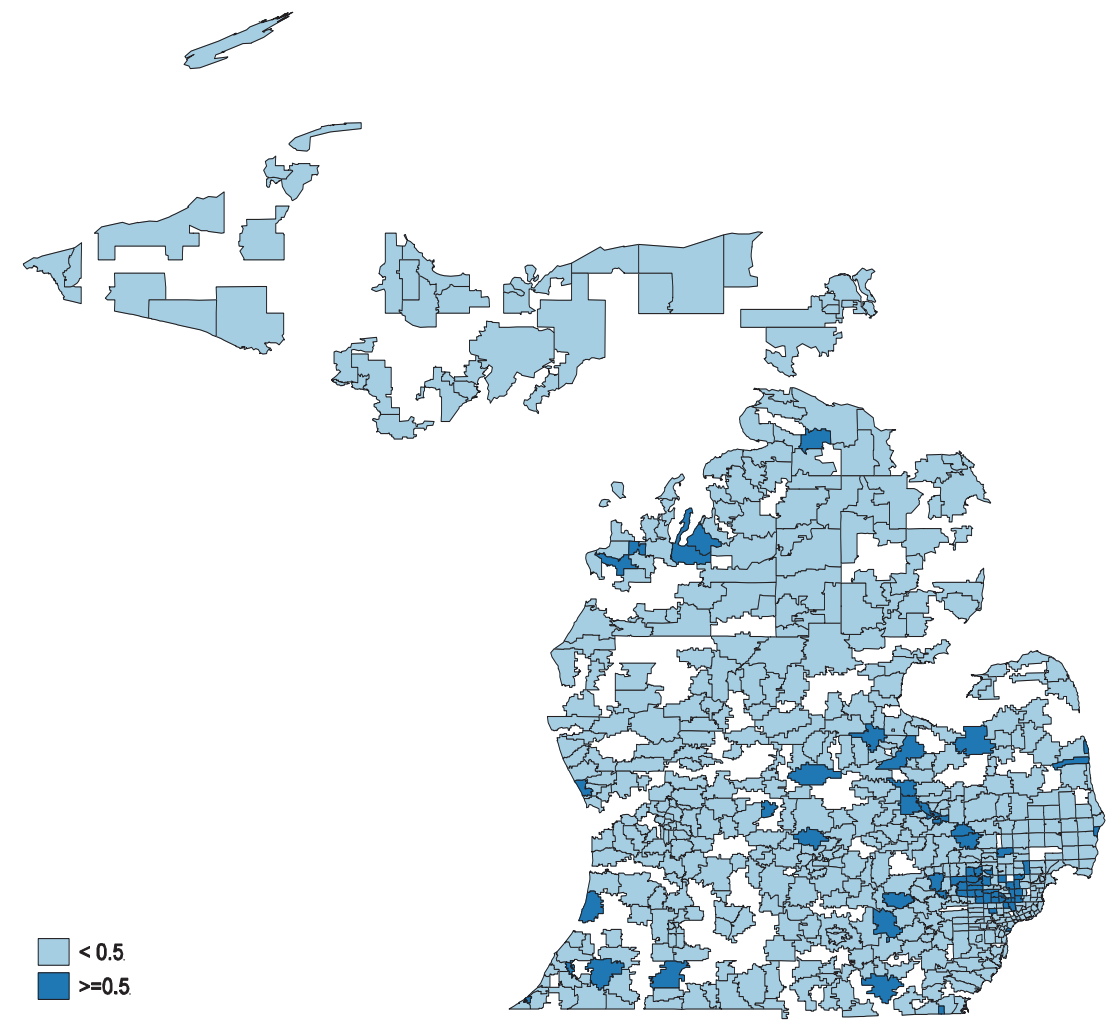

Source: Author's calculations using the 2000 Census SF3 file 


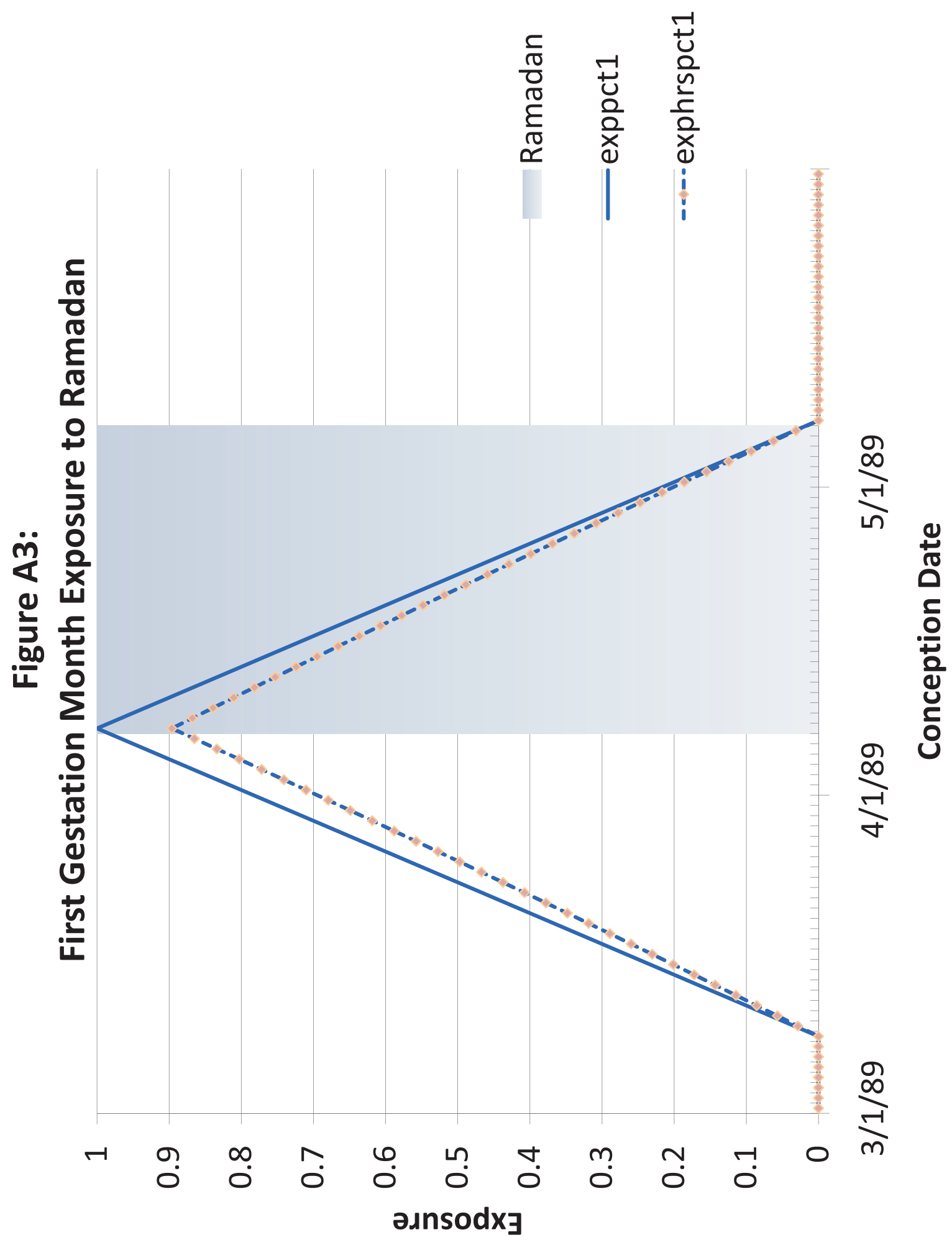




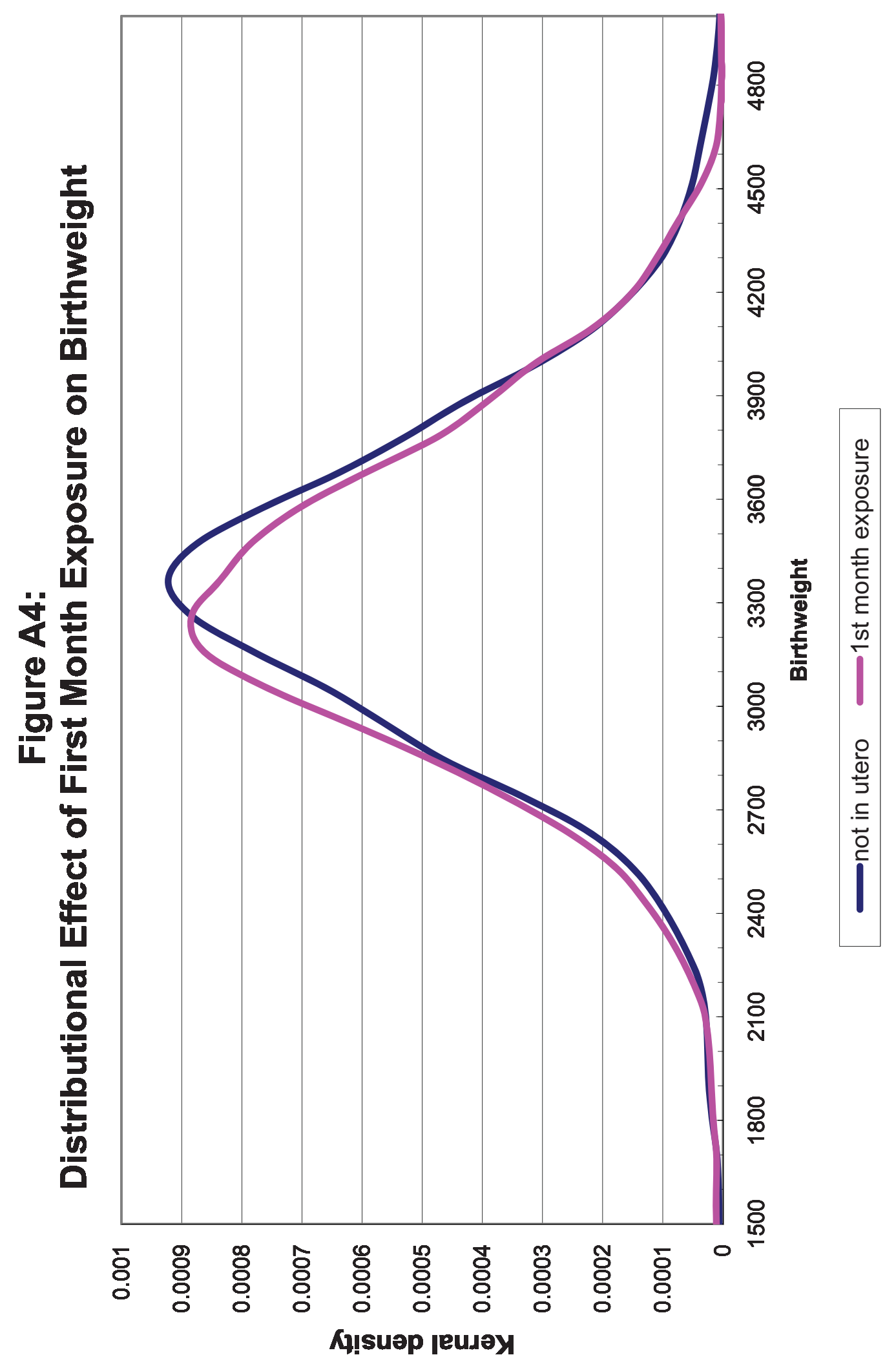

